\title{
The Frequency of Cyclonic Wind Storms Shapes Tropical Forest Dynamism and Functional Trait Dispersion
}

\author{
J. Aaron Hogan 1,*, Jess K. Zimmerman ${ }^{2}$, Jill Thompson ${ }^{3}$, María Uriarte ${ }^{4}$, Nathan G. Swenson ${ }^{5}$, \\ Richard Condit 6,7, Stephen Hubbell ${ }^{8}$, Daniel J. Johnson ${ }^{9}$, I Fang Sun ${ }^{10}$, \\ Chia-Hao Chang-Yang ${ }^{10}$, Sheng-Hsin Su ${ }^{11}$ (D), Perry Ong ${ }^{12}$ (D), Lillian Rodriguez ${ }^{12}$, \\ Carla C. Monoy ${ }^{13}$, Sandra Yap ${ }^{14}$ and Stuart J. Davies ${ }^{15}$
}

1 Department of Biological Sciences, International Center for Tropical Botany, Florida International University, Miami, FL 33175, USA

2 Department of Environmental Science, University of Puerto Rico-Río Piedras, San Juan, PR 00936, USA; jesskz@ites.upr.edu

3 Centre for Ecology \& Hydrology, Penicuik, Midlothian EH26 0QB, UK; jiom@ceh.ac.uk

4 Department of Ecology, Evolution \& Environmental Biology, Columbia University, New York, NY 10027, USA; mu2126@columbia.edu

5 Department of Biology, University of Maryland, College Park, MD 20742, USA; swenson@umd.edu

6 Field Museum of Natural History, Chicago, IL 60605, USA; conditr@gmail.com

7 Morton Arboretum, Lisle, IL 60532, USA

8 Department of Ecology and Evolutionary Biology, University of California, Los Angeles, CA 90095, USA; shubbell@eeb.ucla.edu

9 Los Alamos National Laboratory, Los Alamos, NM 87545, USA; djj4tree@gmail.com

10 Department of Natural Resources and Environmental Studies, National Dong Hwa University, Hualien 97401, Taiwan; ifsun@gms.ndhu.edu.tw (I.F.S.); c.h.changyang@gmail.com (C.-H.C.-Y.)

11 Taiwan Forestry Research Institute, Taipei 10066, Taiwan; sush@tfri.gov.tw

12 Institute of Biology, College of Sciences, University of the Philippines Diliman, Quezon City 1101, Philippines; ongperry@yahoo.com (P.O.); ljvrodriguez@gmail.com (L.R.)

13 Center for Integrative Conservation, Xishuangbanna Tropical Botanical Garden, Chinese Academy of Sciences, Menglun 666303, Yunnan, China; carla.monoy@gmail.com

14 Institute of Arts and Sciences, Far Eastern University, Manila 1008, Philippines; sandralimyap@yahoo.com

15 Center for Tropical Forest Science-Forest Global Earth Observatory, Smithsonian Tropical Research Institute, Washington, DC 20560, USA; DaviesS@si.edu

* Correspondence: jhogan@fiu.edu; Tel.: +1-970-485-1412

Received: 5 May 2018; Accepted: 3 July 2018; Published: 5 July 2018

\begin{abstract}
As cyclonic wind storms (hurricanes and typhoons) increase in frequency and intensity with climate change, it is important to understand their effects on the populations and communities of tropical trees they impact. Using tree demographic data from four large, tropical forest dynamics plots that differ in cyclonic storm frequency, we compare tree population and community dynamics. Additionally, we assess the effect of cyclonic storms on three functional traits, specific leaf area, wood density, and tree height of the dynamic tree assemblages. Mortality, growth and recruitment rates and the intrinsic rates of population growth of species differed across the plots, and were most dynamic, especially for stems 1-2 cm in diameter, at the plot which had an intermediate level of cyclonic storm frequency. Functional assemblages of species had the greatest degree of temporal variation in relation to disturbance, as measured by the change in functional divergence for the two plots with more intermediate cyclonic storm recurrence. Therefore, cyclonic storms affecting these plots generally have a greater effect on forest composition and dynamism than comparable cyclonic storms do on the plot which experiences cyclonic storms more frequently. Thus, we provide some evidence that community-wide demographic resistance to cyclonic storms is generally lower at an intermediate frequency of storms. While cyclonic storm strength and timing are important determinants of the
\end{abstract}


within forest variation in tree dynamics and functional trait assemblages, we also show that cyclonic storm timing and frequency shapes tropical forest dynamics and functional composition across forests. We conclude that, over a given time interval, sites with intermediate levels of damaging cyclonic wind disturbance express a greater potential for life-history variation in the forest community, when compared to sites with less or more frequent disturbance.

Keywords: cyclonic wind disturbance; hurricanes; typhoons; forest resistance; forest demography; tree mortality; tree growth; functional traits; Luquillo; Fushan; Palanan; Barro Colorado Island

\section{Introduction}

\subsection{Cyclonic Wind Disturbances Shape Forest Structure and Dynamics by Influencing Tree Community Demographics and Functional Composition}

Cyclonic wind storms (hurricanes and typhoons) are large-area disturbances [1] that occur at different intervals in different parts of the world and play a key role in shaping the structure and diversity of the world's forests [2-7]. These storms cause structural damage to individual trees, change resource distributions throughout the forest (e.g., biomass, light, and nutrients) and act as a driver of ecological re-organization [8,9]. Although at the landscape scale cyclonic storms may appear indiscriminate in their damage to the vegetation (Figure 1), the different susceptibilities of individual trees to damage [10], and variability in tree recovery across species have been well documented $[6,11,12]$. Cyclonic storms interact with the landscape topography and vegetation distribution to create a patchy spatial structure of disturbance, which further modulates their effects on the tree community [13-15]. Within a few years, most visible effects of a cyclonic storm (e.g., defoliation, tree windthrow, canopy gap formation, or major population fluctuations) disappear as the forest recovers. However, the less-obvious effects (e.g., increased habitat variability, changes to the abiotic environment, delayed stem mortality, and community selection) continue to shape forest structure and the successional trajectory of forest recovery for many years $[1,16]$.

The effects of cyclonic storms on tree communities can be classified into two phases. Firstly, the immediate effects originating from the disturbance event itself, and secondly, the longer-term effects, which continue to influence forest structure, composition, and functional diversity at longer timescales. The main immediate effect results from direct wind damage to tree stems and crowns, and forest canopies $[2,3,11]$. Cyclonic storms act as a selective force by culling individual trees susceptible to damage [6]. The remaining tree community has a relatively higher number of species and individuals more resistant to high wind, for example, species with dense wood and compact canopies, or individuals with limited topographic exposure and deep roots [12,17]. In the Luquillo Experimental Forest of Puerto Rico (LEF), pioneer species, such as Cecropia with its low wood density, were more damaged and had higher mortality rates after Hurricane Hugo struck the forest in 1989 [18].

Thus, the disturbance effects of a damaging cyclonic storm interact with the life-histories of tree species to shape population and community demographics. In the LEF, many of the pioneer species that suffered severe damage during Hurricane Hugo and had high mortality soon afterward, later recruited at high densities. These pioneer species, then, had high rates of sapling mortality as the forest thinned over time [19]. In other words, trees with pioneer life-histories have the potential to be both more damaged during and have high degrees of negative density dependence following cyclonic storms. However, the effect of hurricanes on pioneer species is contingent on forest structure, successional stage, and community composition. Thus, the long-term effects of cyclonic storms on tree communities extend for years to decades and likely vary with the frequency of storm recurrence. For example, in a Jamaican forest, Hurricane Gilbert caused a reduction in growth rates of damaged trees for 11 years following the storm and increased the mortality rate of damaged stems two to eight-fold for 19 years [20]. 


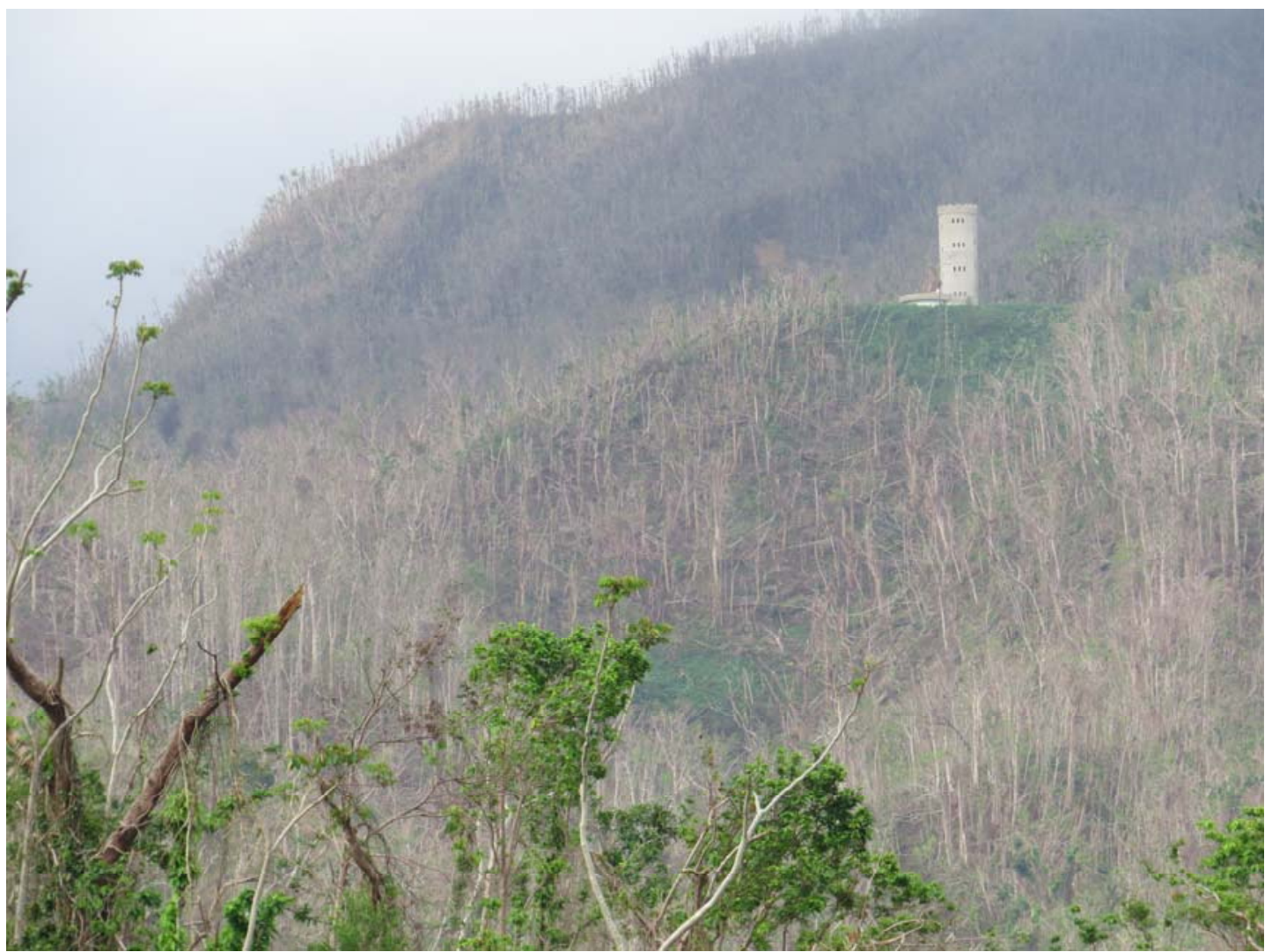

Figure 1. Damage to the forest caused by Hurricane Maria which struck El Yunque National Forest (also known as the Luquillo Experimental Forest) on the morning of 20 September 2017, with sustained winds of 135 knots and maximum wind speeds of 152 knots. The photograph was taken on 10 November 2017, by Dr. Shelia Ward. The 69-foot tall US Forest Service's Yokahu Tower stands in the distance.

Cyclonic storms also shape the functional composition of forests in space and time. Cyclonic storms create selection pressures, both in the short term via mortality and reduced reproduction and over the longer-term through facilitated recruitment, favoring pioneer species with less dense wood, higher specific leaf area and other functional traits associated with a pioneer life-history (e.g., low seed mass) $[5,16,17,21]$. Via canopy defoliation, cyclonic storms directly increase light penetration into the forest, which can result in an increase in the specific leaf area of surviving trees and recruits [12,22]. Forest stature, the successional composition of the community (i.e., the proportion of pioneer species), and the amount of time since the last major cyclonic storm control the magnitude of tree community selection toward pioneer species for each storm $[9,12,13]$. That is, a forest that was recently affected by a strong, damaging cyclonic storm, should experience a weaker effect from a subsequent cyclonic storm if the forest only has a short time to recover between storms (i.e., less than 10 years).

In this light, we can view cyclonic storms in a disturbance ecology framework, that incorporates forest community resistance (i.e., the ability of a forest community to resist alteration in species community composition via large fluctuations in population and community demographic rates) [23] in relation to the cyclonic storm disturbance regime. We advocate a holistic understanding of forest community responses to windstorm disturbance as a 'tapestry' with many parts, incorporating historical contingencies, disturbance legacy effects, population dynamics and uncertainty, the magnitude and duration of the cyclonic storm, and cyclonic storm recurrence that are interwoven to shape to the structure, demographic processes, and the functional composition of forests over time [24]. 


\subsection{Cyclonic Wind Disturbance Frequency and Forest Resistance}

Due to the synergistic nature of compound disturbances [25-27], the length of recovery time between cyclonic storm return can affect the structure and diversity of forests, through interactions with the population dynamics of species over time [28]. For example, results from the SORTIE forest simulator parameterized with data from the Luquillo Forest Dynamics Plot (Puerto Rico) showed that more frequent hurricanes with shorter intervals between storms promoted the coexistence of rare species that were associated with low-intensity land-use legacies [29], thereby preserving the distinct forest communities created by past land use. A separate study in a Jamaican forest showed that less diverse forests were more resistant to cyclonic storms [30], highlighting the fact that late-successional, shade-tolerant species with dense wood and large canopies are more susceptible to wind damage in mature, older forests. The compound effect of disturbances, especially the idea of the cumulative, and often non-additive effects of multiple wind disturbances, is logical because of the way that differences in the strength of cyclonic storms interact with the tree species, their stature and the amount of stand biomass to create a wide variability in disturbance effect, even within a single forest stand [31,32].

More exposed trees (e.g., trees that grow at forest edges, in shallow soil areas, in gaps, or extend above the forest canopy) are often more susceptible to wind-associated damage. During storms there may be a "domino effect" whereby exposed trees damage the immediate forest canopy and weaken the root systems of surrounding trees [33,34]. It follows that when there is only a short interval between storms (i.e., 10 years or less), the second storm may cause less damage as exposed trees prone to damage may have already been removed from the population. On the other hand, given a longer interval between storms (i.e., 40-50 years), the trees damaged during the first storm may be affected by fungal infections or stem breakage, making them more prone to damage by the second storm. Furthermore, changes in community composition, like the ingrowth of pioneer species and their lifecycle timing influence the magnitude of the disturbance effect. Observations of the interdependence of sequential storms and the damage they cause have been assumed for some time [35] and have been explored for the Luquillo plot [24]. Now that we have longer-term data that encompasses two significant hurricanes for Luquillo and other forests, we can evaluate the short and long-term effects of cyclonic storms, and how these may differ between the two global biogeographic regions that vary in cyclonic storm recurrence and intensity—the Caribbean versus the south-western Pacific.

\subsection{Predictions for Forest Dynamism and Functional Composition with Varying Cyclonic Storm Recurrence}

We use tree census data from four permanent, large forest dynamics plots (FDPs) in tropical forests that vary in cyclonic storm frequency and intensity to investigate how disturbance frequency shapes forest resistance. We define forest resistance as the ability of the tree community to resist demographic and compositional change in relation to structural damage of a cyclonic storm. We consider two questions, one in relation to the population demographics of species, including tree species mortality and population growth rates over time, and another that addresses changes in the functional composition of small patches (i.e., $400 \mathrm{~m}^{2}$ quadrats) over time:

(1) Do forests that have storm recurrence intervals that coincide with the time to reproductive maturity of tropical trees show more variable demographics than forests with more frequent or no cyclonic storms?

(2) Do forests that have storm recurrence intervals that coincide with the time to reproductive maturity of tropical trees show greater changes in functional community composition (i.e., more variation in species life-history strategy per unit area over time) than forests with more frequent or no cyclonic storms?

We use an estimate of about 50 years as the time it takes for a tropical tree to reach to reproductive maturity and full adult height and stature [36]. We expected FDPs with recurrence intervals of damaging cyclonic storms closer to 50 years to show stronger dynamics (greater mortality, recruitment, and population growth rates) than those that have more frequent storm recurrence intervals (e.g., 
10 years). The logic is that cyclones that occur at similar timescales to the maturation of tropical trees have more damaging effects than ones that occur at shorter intervals, in an analogous way to the amount of grass that is trimmed, when mowing a law after a month versus a week. We hypothesized that FDPs with more frequent cyclonic storms would be more stable in their functional composition than FDPs with less frequent cyclonic storms when affected by a comparable storm, as illustrated by relatively less change in tree functional composition for a given change in forest structure, such as biomass loss. Here, we remove the varied effects of disturbance among storms, between sites and in space, effectively standardizing to the resultant effect of disturbance on the change in forest biomass, which is then related to the change in the functional composition of the community at the same spatial scale. This is important because it permits comparison across forests with historically different disturbance regimes related to cyclonic storm recurrence, with implications of how forest dynamics might change if cyclonic storms increase in frequency and intensity.

\section{Materials and Methods}

\subsection{Sites and Tree Census Methods}

Plots were chosen based upon their cyclonic storm disturbance regime. Three of the four FDPs Luquillo (Puerto Rico), Palanan (Philippines), and Fushan (Taiwan) are strongly affected by cyclonic storms while Barro Colorado Island (BCI) has never witnessed a large cyclonic storm of the magnitude experienced by the other three FDPs in the modern meteorological record (Table 1). In each FDP, all stems $\geq 1 \mathrm{~cm}$ diameter at $1.3 \mathrm{~m}$ height ( $\mathrm{dbh}$-diameter at breast height), were number tagged, mapped, identified to species, and measured at approximately 5 years intervals [37], in accordance with the Center for Tropical Forest Science (CTFS) methodology [38]. We use tree census data over six census intervals for BCI (1982-2010) [39], four for Luquillo (1990-2011) [40], three for Palanan (1994-2010) and two for Fushan (2004-2014). The BCI FDP is 50-ha, Fushan is 25-ha, and Palanan and Luquillo are both 16-ha, however for the first census interval at Palanan we use data from 8-ha, because the FDP was initially smaller and expanded to 16-ha in 1998. Although the plot sizes differ, sample sizes of all the plots are sufficiently large (i.e., 100,000 stems) to detect population fluctuations in even uncommon species. Tree diversity has ranged between 291 and 297 species at BCI [39], between 113 and 143 species at Luquillo [24], between 308 and 323 species at Palanan [41], and between 107 and 111 at Fushan [42].

All FDPs are in broadleaf, evergreen forest in tropical climates; however, their environments do vary. Fushan, Palanan, and Luquillo are located on islands with mountainous topographies, whereas BCI was established on a flatter plateau area of lowland forest within the Panama Canal. Mean annual precipitation and temperature also differ across the FDPs, with BCI being the warmest, driest plot, and Fushan the coolest, wettest (Table 1). The soils at Fushan are very acidic with $\mathrm{pH}$ value between 3 and 4 and are phosphorus-poor [42]. The soils at Luquillo are highly-weathered tropical clays with low fertility [43]. At Palanan, the soils are clay-derived tropical soils, but are more heterogeneous across the plot including exposed shale outcroppings on ridges to more fertile humus-rich clays in valley areas [44]. The soils at BCI are slightly more fertile than the other three FDPs and are classified primarily as Ava Red Clays with some areas having fine tropical Brown Soils [45]. 
Table 1. Site locations, mean annual temperature and precipitation and mean \pm standard error of cyclonic storm metrics from the IBTrACS database [44] from 1982-2015 for all storms within a hurricane-force wind (64 knots) storm radius ( $225 \mathrm{~km}$ ). Cyclonic storm metrics shown are storm recurrence frequency, closest storm, average storm distance, highest estimated wind velocity, and average estimated wind velocity.

\begin{tabular}{|c|c|c|c|c|c|c|c|c|}
\hline Site & Location & $\begin{array}{l}\text { Mean Annual } \\
\text { Temperature }\left({ }^{\circ} \mathrm{C}\right)\end{array}$ & $\begin{array}{c}\text { Mean Annual } \\
\text { Precipitation }(\mathrm{mm})\end{array}$ & $\begin{array}{l}\text { Average Number of } \\
\text { Storms per Year } \\
\text { (1982-2015) }\end{array}$ & $\begin{array}{l}\text { Nearest Storm } \\
(\mathbf{k m})\end{array}$ & $\begin{array}{l}\text { Average Storm } \\
{\text { Distance }(\mathbf{k m})^{\dagger}}^{\dagger}\end{array}$ & $\begin{array}{l}\text { Highest Estimated } \\
\text { Wind Velocity (kt) }\end{array}$ & $\begin{array}{l}\text { Average Estimated } \\
\text { Wind Velocity }(\mathbf{k t}) \S\end{array}$ \\
\hline $\mathrm{BCI}$ & $9^{\circ} 10^{\prime} \mathrm{N}, 79^{\circ} 50^{\prime} \mathrm{W}$ & 27.1 & 2551 & $0.4 \pm 0.2$ & 102 & $168 \pm 12$ & 85 & $35.3 \pm 5.3$ \\
\hline Luquillo & $18^{\circ} 20^{\prime} \mathrm{N}, 62^{\circ} 49^{\prime} \mathrm{W}$ & 22.8 & 3548 & $3 \pm 1$ & 17 & $148 \pm 6$ & 135 & $63.4 \pm 3.1$ \\
\hline Palanan & $17^{\circ} 12^{\prime} \mathrm{N}, 122^{\circ} 23^{\prime} \mathrm{E}$ & 26.1 & 3218 & $9 \pm 1$ & 20 & $151 \pm 3$ & 125 & $64.9 \pm 1.3$ \\
\hline Fushan & $24^{\circ} 34^{\prime} \mathrm{N}, 121^{\circ} 34^{\prime} \mathrm{E}$ & 18.2 & 4271 & $13 \pm 2$ & 6 & $139 \pm 3$ & 125 & $62.5 \pm 0.9$ \\
\hline
\end{tabular}

${ }^{\dagger} \max 225 \mathrm{~km} .{ }^{\S}$ estimated wind velocity at the site based on the square of the distance from the site to the eye of the storm. 


\subsection{Functional Trait Data}

We used three plant functional traits that summarize the majority of the functional variation in plant life-history strategies [46], especially with respect to tropical trees [47]: (1) specific leaf area (SLA) - the per unit mass, carbon-investment in photosynthetic tissue; (2) wood density (WD) - the mass per volume investment in tree structure; and (3) tree height $(\mathrm{H})$ - a trait related to competitive ability, seed dispersal, longevity, and resource acquisition. SLA and $\mathrm{H}$ tend to be positively correlated with growth rates, whereas WD is typically negatively correlated with growth rates [47,48]. WD and growth rates function as traits of trees that characterize species resistance to cyclonic storm damage, in that species with low WD and faster growth rates resist damage less than species with higher WD and slower growth rates [17], but more importantly they allow for the characterization of species along a fast-slow continuum which is indicative of resource-use strategies, allowing for the extrapolation of species trends in population dynamics to community variation. All traits were collected locally at each FDP; trait data were collected by Wright et al. [48] for BCI, Swenson et al. [49] for Luquillo, Monoy et al. [21] for Palanan, and Sun et al. for Fushan see [50,51].

\subsection{Characterizing the Disturbance Regimes}

To characterize the nature of wind disturbance at each site, we queried the IBTrACS database [52] that contains meteorological records for all tropical cyclonic wind storms since 1942. We used data on cyclonic storms whose center passed within $225 \mathrm{~km}$ of each FDP (the maximum radius of hurricane force winds-33 $\mathrm{m} \mathrm{s}^{-1}, 64$ knots, or $73 \mathrm{mph}$-of cyclonic storms [53]) since 1982 (when the BCI FDP was established). We estimated the maximum surface wind speed experienced at the plot location $\left(V_{\text {site }}\right)$ using the following equation from [53]: $V_{\text {site }}=\left(\frac{V_{\max }}{d}\right)^{0.5}$, where $V_{\max }$ is the maximum storm windspeed and $d$ is the distance from the site to the eye of the storm, assuming a $10 \mathrm{~km}$ eyewall. Next, we considered several metrics to characterize the cyclonic storm regime at each site: the average number of storms per year, the average storm distance between the storm eye and the plot, the distance of the nearest storm from the plot, and the estimated mean and maximum wind velocities.

\subsection{Analyses of Forest Demographics}

We were interested in how the variability in cyclonic storm regimes affected stand level dynamics of tropical forests. We first looked at mortality and growth of stems (as opposed to individuals) in relation to stem diameter. For each geometric size class from 1 to $128 \mathrm{~cm}$ (stems $1-2 \mathrm{~cm},>2-4 \mathrm{~cm}$, $>4-8 \mathrm{~cm},>8-16 \mathrm{~cm},>16-32 \mathrm{~cm},>32-64 \mathrm{~cm},>64-128 \mathrm{~cm}$, and $>128 \mathrm{~cm}$ ) and each census interval, the plot level mortality rate was calculated as: $\frac{(\ln (N)-\ln (S))}{T}$, where $N$ is the number of stems alive in the first census of the interval, $S$ is the number of surviving stems, and $T$ is the length of the census interval in years. We calculated plot level recruitment rates of stems to the $1 \mathrm{~cm}$ dbh size class using: $\frac{(\ln (N+R)-\ln (N))}{T}$, where $N$ and $T$ are consistent with the equation for mortality and $R$ is the number of recruits registered in the second census of the interval. Similarly, again for each geometric size class and census interval, the absolute growth rate for each stem was calculated as: $\frac{(d b h 2-d b h 1)}{T}$, where $d b h 1$ and $d b h 2$ are the diameters at the first and second census of each census interval, and $T$ is, the time between censuses in years. Mortality and growth rates were calculated for each stem separately, and then grouped according to size class.

We also quantified how the abundance of individual trees changed in the FDPs by modeling $r$-the intrinsic rate of population growth of each species. Mathematically, $r$ is $\log (\lambda)$, where $\lambda$ is the finite population growth rate, or the proportional change in population size $(N)$ from one time period to the next [54], and can be represented for every $i$-th species from census $t$ to $t+1$ as: $r_{i t}=\frac{1}{\Delta T_{i t}} \log \left(\frac{N_{i, t+1}}{N_{i t}}\right)$ [54]. Tropical cyclones may have different effects on the growth and survival of tree species, and the overall effect of repeated storms (i.e., the cyclonic storm disturbance regime) could potentially be expressed in interspecific variability in population sizes and their dynamics over time. From the perspective of population dynamics of trees, $r$ provides information on immigration, 
fecundity, seed dispersal and recruitment [55]. When a population is stable, $\lambda=1$ and $r=0$, and $r$ can be averaged across populations of individual species to find the mean rate of population change for all species in the community. Prior to model fitting of the intrinsic rates of population growth, the variability in the change in abundance of each species was separated into environmental and neutral (i.e., stochastic) portions [56], and the neutral portion of the demographic variance was removed. A binomial error structure is used in estimating the population growth rate from the species abundance data, because the demographic variance is assumed to follow a binomial distribution; a mortality rate constant for each species is fit at the same time, see [56].

Then, the frequency distribution of the intrinsic rates of population growth for all species in the each plot was fit using a hierarchical asymmetrical Laplace (i.e., exponential) model: $p(x)=\left\{\begin{array}{l}a e^{\left(b_{1}(x-c)\right)}, \text { where } x<0 \\ a e^{\left(b_{2}(x+c)\right)} \text {, where } x>0\end{array}\right.$, where $a$ is a constant of integration (not used in modeling) and $b_{1}, b_{2}$, and $c$ are fitted model parameters see Appendices S4 and S5 in [56]. The $c$ parameter is the origin, and is always fit very close to zero, and the parameters $b_{1}$ and $b_{2}$ together define the breath and asymmetry of the distribution of intrinsic rates of population growth for the community (see Supplementary Material). This effectively represents the plot-wide distribution of intrinsic rates of population growth. For all census intervals for each FDP (six for BCI, four for Luquillo, three for Palanan, and two for Fushan), we correlated intrinsic rates of population growth and stem mortality rates from the demographic model with functional traits to understand how species life-histories, inferred from these three functional traits, were related to disturbance regime. The justification for the trait-demographic rate correlations is twofold; first, to determine if functional traits do relate to tree demographic responses, and second, to examine the nuances in the relationships between species life-histories and their functional traits over time in relation to wind disturbance.

\subsection{Linking Stand Demographics to Functional Traits: Changes in Biomass and Functional Divergence}

It has been suggested that when examining cyclonic storm effects on forests, that changes in stand biomass or basal area are ideal ways to quantify cyclonic storm effect, and more useful than changes in stem densities or other measures of forest structure [57]. We see value in both approaches, thus, we calculated the aboveground biomass for all individuals (including multiple stems on individual trees) within each FDP using the allometric equation for tropical trees developed by Chave et al. [58]. The equation in Chave et al. [58] considers the tree diameter and the wood specific gravity by species; we used the CTFS database for wood specific gravity values that includes the wood density for the majority of species in our FDPs (http://ctfs.si.edu/Public/Datasets/CTFSWoodDensity). In cases where the wood density of species in a particular plot was unknown, the mean wood density value for that plot was used. These cases were few, numbering fewer than 10 species for BCI and Palanan, principally rare species. Fushan and Luquillo had complete WD data for their plant communities.

Spatial-scale is an important consideration when interpreting changes in forest biomass. Although the patch size dominating the landscape in relation to disturbance effect is known to vary across forests and between disturbances, we looked at the effect of cyclonic storms on an intermediate patch size of $20 \times 20 \mathrm{~m}\left(400 \mathrm{~m}^{2}\right.$ area). The dominant patch size of a cyclonic storm damage at Luquillo is $1000 \mathrm{~m}^{2}$ (0.1 ha) [14], while treefall gaps at BCI range from 20-705 $\mathrm{m}^{2}$ [59]. Nevertheless, examining stand dynamics at the quadrat level fits well within the usual range of forest gap sizes sensu [60], where a gap is defined as an area of forest or where a tree has fallen down to leave a hole in the forest canopy and has no trees taller than $2 \mathrm{~m}$; this allows for a comparison of forest dynamics across sites. We limited the quadrat biomass fluctuation to $\pm 10 \mathrm{~kg} 400 \mathrm{~m}^{-2}$, which is equal to the greatest change in biomass for a quadrat of the Fushan plot, which had the smallest biomass changes.

As a measure of forest resistance to cyclonic storms across plots, we related a given change in biomass to the relative change in the functional composition of the community. At the quadrat level, using tree species abundance and the three functional traits (SLA, WD, and H), we calculated the functional divergence (FDiv) for each plot over time. Functional divergence is defined as: 
$F D i v=\frac{\Delta d+\overline{d G}}{\Delta|d|+\overline{d G}}$, where $\Delta d$ is the sum of abundance-weighted deviances from the functional center of gravity; $\Delta|d|$ is the absolute value of the sum abundance-weighted deviances from the functional center of gravity, and $\overline{d G}$ is the mean distance of each species to the functional center of gravity [61]. FDiv is the multivariate analog of the weighted-mean absolute variation of a functional trait of an assemblage (i.e., community-weighted variability), and it characterizes how species abundances are distributed within a defined functional trait space [61]. In this case, it is a three-axis functional trait space encompassing the community range in SLA, WD, and H. FDiv is often interpreted as the degree to which the abundance distribution of an assemblage maximizes functional trait differences (i.e., permits for a variety of ecological life-histories) [61,62]. It is unaffected by the species richness of the assemblage and can change without a change in either functional richness or evenness [62].

Cyclonic storms affect the functional trait composition of the forest community, by causing both greater mortality of pioneers in the short term, and promoting their existence over the longer term, through regeneration of pioneers in storm-created gaps. Pioneer species have the functional signature of high SLA, low WD and often grow tall, so their response to disturbance forms one bound on the functional divergence of the community. SLA and $\mathrm{H}$ were $\log$ transformed, and data for all three traits were centered and scaled prior to the calculation of FDiv using the 'FD' package [63] in R v.4.3.3 [64]. We used a null model that randomized species identity on the functional trait matrix [65] 999 times and then calculated the standardized effect size (SES) of FDiv at the quadrat level by subtracting the null model mean value from the observed value and dividing the difference by the standard deviation of null model values.

Positive FDiv values signify that the most abundant species in the assemblage exist on the edges of the functional trait space, having extreme functional trait values in relation to the other species [62]. This can reflect niche partitioning by competitive exclusion or a high degree of environmental heterogeneity resulting in an assemblage with a diversity of ecological strategies. On the other hand, negative FDiv values represent very little functional differentiation among the most abundant species in the assemblage, representing in a narrower range of ecological strategies, which could arise via environmental filtering or a similar selective process [61]. In the context of our questions and hypotheses, an assemblage was deemed resistant to cyclonic storm effects, if for a given change in quadrat biomass the change in functional composition ( $\triangle \mathrm{SES} F D i v$ ) was close to zero. Quadrats with negative $\triangle S E S F D i v$ values are on trajectories where the functional composition is becoming more similar. Positive $\triangle$ SES FDiv scores show quadrats where the species composition in the functional trait space is diverging over a particular census interval.

\section{Results}

\subsection{Disturbance Regimes}

Cyclonic storm frequency and intensity data showed that the three FDPs that experience cyclonic storms (Luquillo, Palanan, and Fushan) have varied cyclonic storm recurrence and intensity (Table 1). Since 1982, the number of cyclonic storms that have passed within $225 \mathrm{~km}$ (the maximum radius of hurricane-force wind for a tropical cyclone [53]) of each FDP is 13 for BCI, 98 for Luquillo, 273 for Palanan, and 373 for Fushan. The IBTrACS database [52] registered about three times as many storms per year for the Palanan FDP and about four times as many storms per year for the Fushan FDP than for Luquillo. BCI experienced less than a single storm per year, none of which came within $100 \mathrm{~km}$ of the plot. Cyclonic storms did pass very close to Palanan and Luquillo, and directly over Fushan during the study period. Estimated average wind velocities of cyclonic storms experienced by Luquillo, Palanan, and Fushan were comparable, around 64 knots, which is the equivalent of a Category 1 storm on the Shaffir-Simpson scale, but were roughly half that for BCI measuring about 35 knots (Table 1).

Notably, the main difference in cyclonic storm regimes among the three storm-affected FDPs is the number of storms per year (Table 1). Luquillo experienced about 3 cyclonic storms per year within 
hurricane-force wind distance; Palanan experienced about 9 storms; and Fushan saw 13. No major cyclonic storm has ever damaged the forest of the BCI FDP since its establishment. For Luquillo, two major hurricanes have caused stem damage: Hugo in September 1989 (prior to the first census in 1990) and Georges in September 1998 (census interval 2). Over the three census intervals for Palanan, three typhoons caused major damage to the plot: Zeb in 1998 (at the beginning of the second census interval), Imbudo in 2003 (during the second census interval), and Mitag in 2007 (during the third interval). Over the two census intervals for Fushan, four typhoons have affected the plot causing various amounts of stem damage, three have occurred in the first census interval, Aere in 2004, and Jangmi and Sinlaku in 2008, and one in the second census interval, Soulik in 2013.

\subsection{Forest Dynamics}

\subsubsection{Stem Dynamics}

Stem mortality and diameter growth rates varied among census intervals and were different across FDPs (Table 2). Plot-wide stem mortality at BCI was stable over time averaging $2.7 \%$ year $^{-1}$ between $^{-}$ 1982 and 2010. Fushan (2004-2014) and Palanan (1994-2010) had identical plot-wide mortality rates at $2.6 \%$ year $^{-1}$. Plot-wide mortality at Luquillo was considerably higher from 1990-2011, averaging $9 \%$ stems year ${ }^{-1}$, and steadily declining from the initial census that was carried out after Hurricane Hugo and captured in the first census the dramatic tree establishment after this storm. Strikingly, stem mortality in the smallest geometric diameter class of stems was nearly an order of magnitude higher at Luquillo in the first few census intervals following Hurricane Hugo (Figure 2) than at either BCI or Fushan. At Luquillo, stem mortality rates in the smallest size classes have slowed over time since the first census interval but have remained higher than at the other three FDPs.

In regard to forest demographics, we were interested primarily in trends in stem mortality but also looked at patterns of recruitment. Recruitment tracked dynamics in stem mortality, with rates being greater in Luquillo in the two census intervals following Hurricane Hugo than at either BCI or Fushan (Table 2). Stem recruitment in the Palanan FDP surged to $20 \%$ year ${ }^{-1}$ after Typhoon Zeb affected the forest, and this was recorded during the first census interval (Table 2). Fluctuations in stem densities (i.e., the sum of mortality and recruitment) were greatest at Luquillo, steadily declining and ranging from -377 to -1242 stems $\mathrm{Ha}^{-1}$ census interval ${ }^{-1}$. Fushan and $\mathrm{BCI}$ have also recorded declines in stem densities since the plots were established. At BCI stem density has steadily thinned over the most recent 20 years. Palanan showed that stem density declined over the first and third census intervals, however there was an increase during the second interval after Typhoon Imbudo. At Luquillo and Fushan, mortality rates were greater for the smaller stems, whereas at BCI mortality rates were similar across stem size classes (Figure 2). On the other hand, at Palanan, several large trees died between the first and second census (1994-1998), making stem mortality in larger size classes appear similar to that of smaller stems, a trend that reduced over time (Figure 2). A more detailed look at the stem dynamics for each FDP revealed that the range in the greatest degree of stem losses ha $\mathrm{h}^{-1}$ for a census interval among plots was -68 for Fushan, -94 for BCI, -95 for Palanan, and -383 for Luquillo (Table 2). The range in maximum stem gains ha ${ }^{-1}$ for a census interval was 45 for Palanan, 118 for BCI, 127 for Fushan, and 341 Luquillo (Table 2). 
Table 2. Census intervals, number of years since last major cyclonic wind disturbance (cyclonic storm), and several forest structural metrics: change in biomass, change in biomass per stem, change in stem density, and stem mortality, recruitment, and growth rates for four permanent forest dynamics plots (FDPs) that span a disturbance gradient: Barro Colorado Island (BCI), Panama, Luquillo, Puerto Rico, Palanan, Philippines and Fushan, Taiwan. See www.forestgeo.si.edu for more information the Center for Tropical Forest Science plot network.

\begin{tabular}{|c|c|c|c|c|c|c|c|c|c|}
\hline Site & $\begin{array}{l}\text { Census } \\
\text { Interval }\end{array}$ & Year Range & $\begin{array}{l}\text { No. of Years Since Last } \\
\text { Major Cyclonic Storm }\end{array}$ & $\begin{array}{l}\Delta \text { Biomass }^{\Delta} \\
\left(\text { tons ha }{ }^{-1} \text { ) }\right.\end{array}$ & $\begin{array}{c}\Delta \text { Biomass Stem }^{-1} \\
\quad \text { (tons ha }^{-1)}\end{array}$ & $\begin{array}{c}\Delta \text { No. Stems } \\
\text { ha }^{-1}\end{array}$ & $\begin{array}{c}\text { Mortality } \\
\text { Rate }\left(\% Y^{-1}\right)\end{array}$ & $\begin{array}{l}\text { Recruitment } \\
\text { Rate }\left(\% \mathrm{Yr}^{-1}\right)\end{array}$ & $\begin{array}{c}\text { Stem Growth } \\
\text { Increment }\left(\mathrm{mm} \mathrm{Yr}^{-1}\right)\end{array}$ \\
\hline \multirow{6}{*}{$\mathrm{BCI}$} & $1^{\$}$ & $1982-1985^{\$}$ & & & & 261 & 0.027 & 0.043 & 1.315 \\
\hline & 2 & 1985-1990 & & -7.95 & -0.077 & 119 & 0.022 & 0.032 & 1.369 \\
\hline & 3 & 1990-1995 & & -2.13 & 0.042 & -212 & 0.028 & 0.020 & 0.803 \\
\hline & 4 & 1995-2000 & & 4.11 & 0.114 & -321 & 0.031 & 0.020 & 0.251 \\
\hline & 5 & $2000-2005$ & & -2.88 & -0.149 & -563 & 0.026 & 0.026 & 0.868 \\
\hline & 6 & 2005-2010 & & -18.72 & -0.136 & -489 & 0.027 & 0.030 & 0.967 \\
\hline \multirow{4}{*}{ Luquillo } & 1 & 1990-1995 & 2 & -5.87 & -0.217 & -1084 & 0.119 & 0.049 & 2.011 \\
\hline & 2 & 1995-2000 & $7^{\mathbb{C}}$ & -11.31 & -0.247 & -377 & 0.105 & 0.092 & 1.868 \\
\hline & 3 & $2000-2005$ & 12 & -13.41 & -0.791 & -1242 & 0.088 & 0.017 & 1.436 \\
\hline & 4 & 2005-2011 & 17 & -14.40 & -0.781 & -477 & 0.048 & 0.014 & 1.050 \\
\hline \multirow{3}{*}{ Palanan } & 1 & 1994-1998 & & 4.82 & 0.262 & -396 & 0.033 & 0.199 & 1.641 \\
\hline & 2 & 1998-2004 & 0 & 12.9 & -0.388 & 978 & 0.023 & 0.064 & 1.174 \\
\hline & 3 & 2004-2010 & 4 & 44.9 & 0.307 & -219 & 0.023 & 0.016 & 1.260 \\
\hline \multirow{2}{*}{ Fushan } & 1 & 2004-2009 & 1 & 9.08 & 0.082 & -86 & 0.023 & 0.031 & 1.242 \\
\hline & 2 & 2009-2014 & 5,0 & 11.84 & 0.147 & -260 & 0.029 & 0.031 & 1.001 \\
\hline
\end{tabular}

$\$$ Due to changes in census methodology between census 1 and 2 for $\mathrm{BCI}$, including the movement of many points of diameter measure, the first census interval for BCI was not used looking at changes in biomass [34]. ${ }^{\complement}$ Hurricane Hugo occurred in September 1989, a category 4 storm that had limited damage to the forest structure of the Luquillo plot [23,27]. 


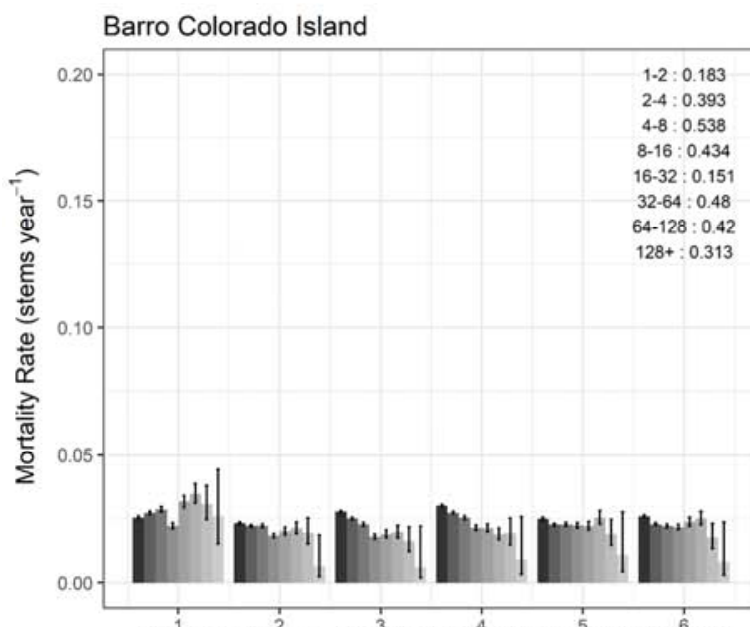

$1982-1985$ 1985-1990 $1990^{\frac{1}{3}}-1995$ 1995-2000 2000-2005 2005-2010

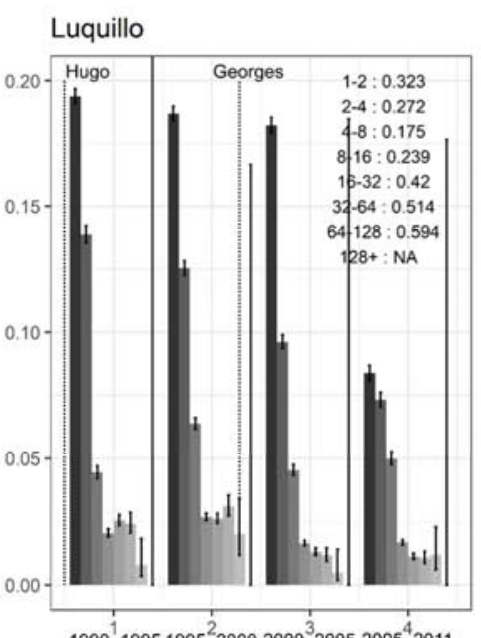

1990-1995 1995-2000 2000-2005 2005-20

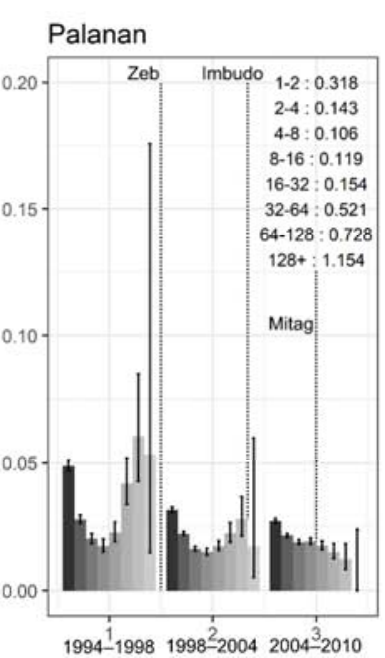

1994-1998 $1998-2004 \quad 2004^{3}-2010$
Fushan

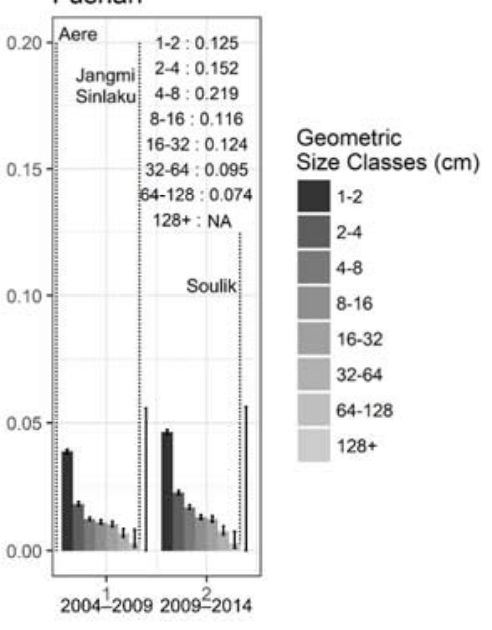

Figure 2. Mortality rates by stem size class for four large FDPs spanning a gradient of cyclonic storm recurrence from infrequent (BCI) to regular (Fushan) (see Table 1). Bars are mean annualized plot wide mortality rates in percent per year ( $\pm 95 \%$ confidence intervals) for that stem size class calculated from roughly 5 -year demographic censuses using CTFS methodology. Numbers in the upper-right corner of each panel are across-census coefficients of variation in stem mortality by size class. Vertical dotted lines with corresponding names indicate the occurrence of major cyclonic storms at each plot. 


\subsubsection{Stem Growth and Biomass Dynamics}

Plot-wide stem growth rates ranged from $0.25 \mathrm{~mm}$ year $^{-1}$ at BCI from 1995-2005, to $>2 \mathrm{~mm}$ year $^{-1}$ in the census interval following Hurricane Hugo at Luquillo (Table 2). Trees at all sites grew at similar rates (Figure 3, Table 2). Additionally, stem biomass dynamics fluctuated over time (Table 2). Over the study period, Luquillo consistently lost biomass, while Fushan and Palanan steadily gained biomass, and biomass at $\mathrm{BCI}$ remained relatively constant. Changes in biomass between census intervals ranged from -91 to $53 \mathrm{~kg} 400 \mathrm{~m}^{-2}$ for BCI, from -22 to $17 \mathrm{~kg} 400 \mathrm{~m}^{-2}$ for Luquillo, from -44 to $57 \mathrm{~kg} 400 \mathrm{~m}^{-2}$ for Palanan, and from -10 to $11 \mathrm{~kg} 400 \mathrm{~m}^{-2}$ for Fushan.

\subsubsection{Population Dynamics}

Intrinsic rates of population growth for BCI species (including all stems $\geq 1 \mathrm{~cm}$ ) ranged from -0.56 for Psychotria hoffmannseggiana (Willd. ex Schult.) Müll.Arg. during the first census interval (1982-1985) to 0.50 for Cecropia longipes Pittier for census interval 4 (1995-2000). At Luquillo, intrinsic rates of population growth varied from -1.24 for Piper umbellatum L. to 0.50 for Palicourea croceoides Ham., both during the first census interval (1990-1995). At Palanan, they were between -0.41 for Maesa denticulata Mez for the first census interval (1994-1998) and 0.43 for Mallotus mollissimus (Geisel.) Airy Shaw., during the second census (1998-2004).

The most negative intrinsic rate of population growth for the Fushan FDP occurred during the second census interval (2009-2014) for Symplocos wikstroemiifolia Hayata and measured -0.49 , and the greatest rate population increase happened during the first census interval (2004-2009) for Euyra loquiana Dunn measuring 0.15. These species represented the trees with the largest degree of demographic responses over time (i.e., the bounds of population growth rates for the exponential model) for each plot, and they are mostly pioneer species of smaller stature (i.e., shrubs) (for complete model output from the fitted asymmetrical Laplace models for intrinsic relates of population growth for each plot by census interval see Supplementary Material). Model estimates for the community average intrinsic rates of population growth of species were consistently greater when considering all stems in the plot, rather than just adult trees ( $\geq 10 \mathrm{~cm}$ dbh) (Figure 4). Differences between the estimates of $r$ for small and large stems were less for BCI, Palanan, and Fushan than for Luquillo (Figure 4). BCI had very stable intrinsic rates of population growth for both small and large stems over time. Luquillo had high variability in the average population growth rates for all stems during the first census interval, a trend that attenuated over time as population growth rates stabilized. Palanan showed some temporal variability in population growth, and Fushan showed increasing variance over its two census intervals.

Pearson correlations of specific leaf area, tree height, and wood density with the population growth and mortality rates of the asymmetric Laplace model, by species, revealed that functional trait differences were more strongly related to mortality rates than they were for population growth rates (Tables 3 and 4). Functional traits had very little correlation with the population growth rates of adult trees (trees $\geq 10 \mathrm{~cm}$ dbh) (right half of Table 3). When a significant relationship was found, WD was most strongly correlated with population growth (Table 3). Also, functional trait correlations with population growth rates of all stems varied in direction over time. For example, at BCI wood density was positively correlated with intrinsic population growth rates of species over the first three census intervals but was negatively correlated in the second three. The three functional traits, SLA, $\mathrm{WD}$, and $\mathrm{H}$, were almost always correlated with the mortality rates of all stems in all forests (Table 4). At Luquillo and Fushan, SLA was not related to the mortality rates of large trees but at Palanan, functional traits were related to mortality rates for the last two census intervals. Tree height was never related to the mortality of large trees at any of the FDPs (Table 4). Finally, at Fushan no traits were statistically significantly correlated with the mortality rates of large trees. 

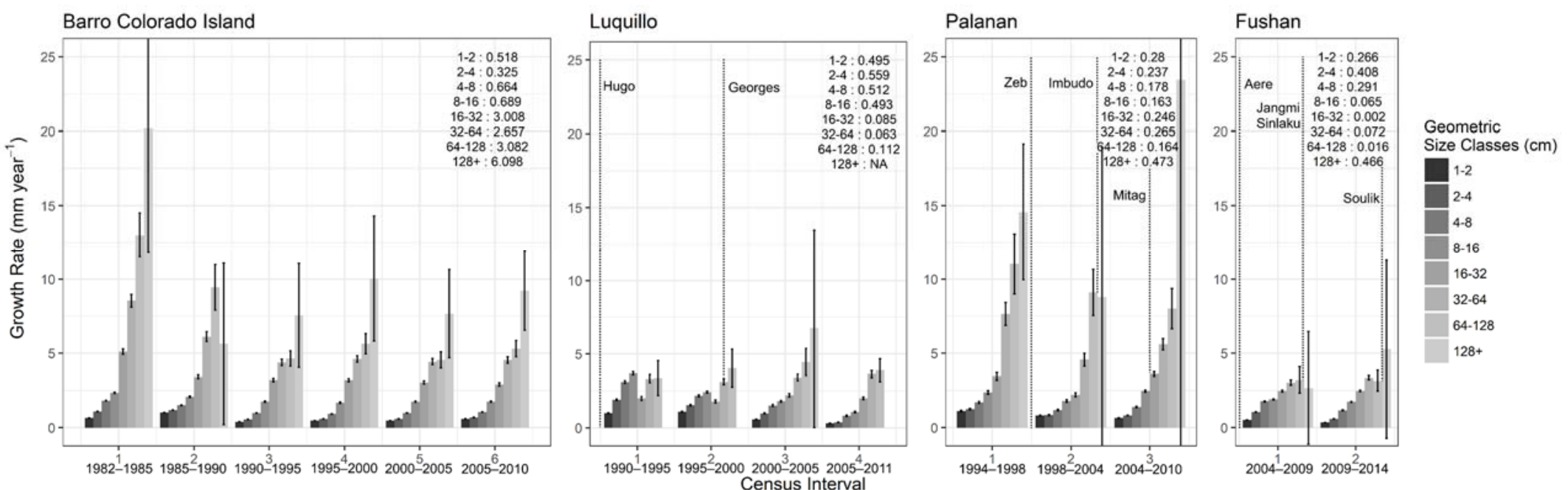

Figure 3. Stem growth rates by size class for the same three large FDPs with differing cyclonic storm recurrence (see Table 1). Bars are mean annualized growth rates in $\mathrm{mm}$ ( $\pm 95 \%$ confidence intervals) from stem diameter measurements taken roughly every 5 years. Similarly, to Figure 2 , inter-census coefficients of variation by size class are shown for each plot in the top-right corner of each panel. Vertical dotted lines with corresponding names indicate the occurrence of major cyclonic storms at each plot. 

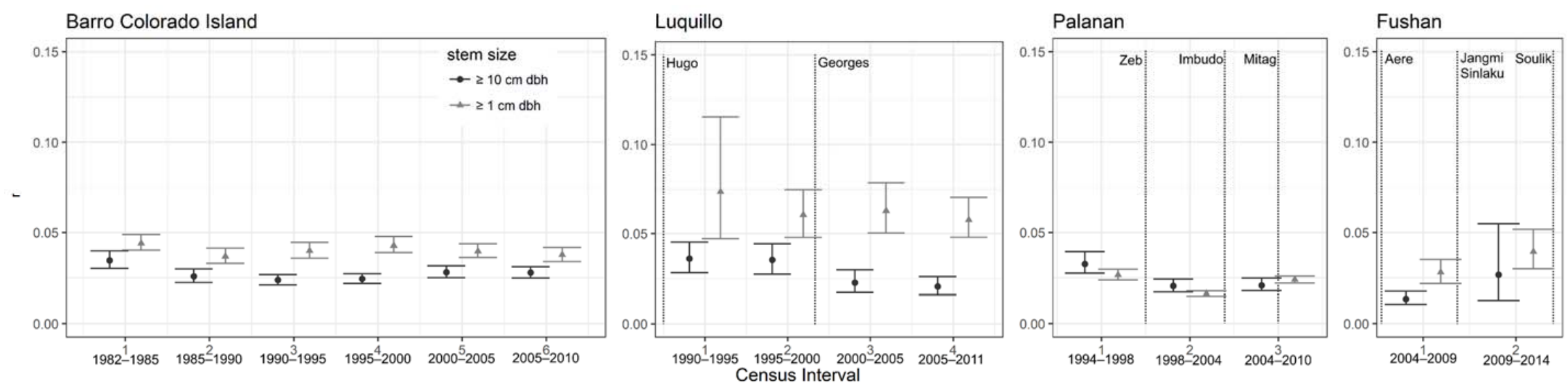

Figure 4. Community average estimates ( $\pm 95 \%$ confidence interval) of annualized intrinsic rates of population growth $(r)$ for all $(\geq 1 \mathrm{~cm})$ and only large $(\geq 10 \mathrm{~cm})$ trees by census interval for four large FDPs with varying cyclonic storm regimes. Plots are organized from least to greatest cyclonic storm frequency from left to right. Vertical dotted lines with corresponding names indicate the occurrence of major cyclonic storms at each plot.

Table 3. Pearson correlation coefficients and their associated probabilities for three functional traits with plot-wide species intrinsic rates of population growth $(r)$ for all stems $(\geq 1 \mathrm{~cm} \mathrm{dbh})$ and large trees $(\geq 10 \mathrm{~cm}$ dbh) from three cyclonic storm-affected permanent forest dynamics FDPs. Statistically significant correlations are bolded and one marginally-significant $(0.05-0.06) p$-value is denoted with $>0.05$.

\begin{tabular}{|c|c|c|c|c|c|c|c|c|c|c|c|c|c|c|}
\hline \multirow{4}{*}{ Site } & \multirow{4}{*}{$\begin{array}{l}\text { Census } \\
\text { Interval }\end{array}$} & \multirow{4}{*}{$\begin{array}{l}\text { Years Since } \\
\text { Last Major } \\
\text { Cyclonic } \\
\text { Storm }\end{array}$} & \multicolumn{12}{|c|}{ Intrinsic Rate of Population Growth $(r)$} \\
\hline & & & \multicolumn{6}{|c|}{ Stems $\geq 1 \mathrm{~cm} \mathrm{dbh}$} & \multicolumn{6}{|c|}{ Stems $\geq 10 \mathrm{~cm} \mathrm{dbh}$} \\
\hline & & & \multicolumn{2}{|c|}{ Specific Leaf Area } & \multicolumn{2}{|c|}{ Tree Height } & \multicolumn{2}{|c|}{ Wood Density } & \multicolumn{2}{|c|}{ Specific Leaf Area } & \multicolumn{2}{|c|}{ Tree Height } & \multicolumn{2}{|c|}{ Wood Density } \\
\hline & & & Pearson's $r$ & $p$ & Pearson's $r$ & $p$ & Pearson's $r$ & $p$ & Pearson's $r$ & $p$ & Pearson's $r$ & $p$ & Pearson's $r$ & $p$ \\
\hline \multirow{6}{*}{$\mathrm{BCI}$} & 1 & & 0.07 & 0.32 & -0.11 & 0.06 & 0.25 & $<0.001$ & -0.03 & 0.75 & -0.06 & 0.40 & 0.11 & 0.11 \\
\hline & 2 & & -0.07 & 0.36 & 0.06 & 0.32 & 0.15 & $<0.01$ & -0.04 & 0.61 & 0.03 & 0.63 & 0.09 & 0.19 \\
\hline & 3 & & -0.23 & $<0.01$ & 0.23 & $<0.001$ & 0.23 & $<0.001$ & -0.06 & 0.45 & 0.09 & 0.16 & -0.04 & 0.54 \\
\hline & 4 & & 0.23 & $<0.01$ & 0.08 & 0.19 & -0.09 & 0.16 & 0.25 & $<0.01$ & -0.01 & 0.86 & -0.16 & $<0.05$ \\
\hline & 5 & & -0.02 & 0.81 & -0.05 & 0.42 & -0.18 & $<0.01$ & -0.13 & 0.09 & 0.12 & 0.07 & -0.01 & 0.27 \\
\hline & 6 & & 0.01 & 0.87 & 0.01 & 0.89 & -0.10 & 0.10 & 0.04 & 0.64 & -0.09 & 0.19 & -0.09 & 0.19 \\
\hline \multirow{4}{*}{ Luquillo } & 1 & 2 & -0.33 & $<0.001$ & 0.17 & $>0.05$ & 0.23 & $<0.01$ & 0.19 & 0.08 & 0.17 & 0.12 & -0.25 & $<0.05$ \\
\hline & 2 & $7^{4}$ & 0.03 & 0.72 & 0.03 & 0.75 & 0.03 & 0.78 & 0.10 & 0.39 & -0.05 & 0.64 & -0.24 & $<0.05$ \\
\hline & 3 & 12 & -0.45 & $<0.001$ & 0.23 & 0.02 & 0.25 & $<0.01$ & 0.17 & 0.14 & 0.05 & 0.65 & -0.02 & 0.87 \\
\hline & 4 & 17 & -0.53 & $<0.001$ & 0.13 & 0.16 & 0.2 & $<0.05$ & -0.20 & 0.07 & 0.15 & 0.18 & -0.06 & 0.62 \\
\hline
\end{tabular}


Table 3. Cont

\begin{tabular}{|c|c|c|c|c|c|c|c|c|c|c|c|c|c|c|}
\hline \multirow{4}{*}{ Site } & \multirow{4}{*}{$\begin{array}{l}\text { Census } \\
\text { Interval }\end{array}$} & \multirow{4}{*}{$\begin{array}{c}\text { Years Since } \\
\text { Last Major } \\
\text { Cyclonic } \\
\text { Storm }\end{array}$} & \multicolumn{12}{|c|}{ Intrinsic Rate of Population Growth $(r)$} \\
\hline & & & \multicolumn{6}{|c|}{ Stems $\geq 1 \mathrm{~cm} \mathrm{dbh}$} & \multicolumn{6}{|c|}{ Stems $\geq 10 \mathrm{~cm} \mathrm{dbh}$} \\
\hline & & & \multicolumn{2}{|c|}{ Specific Leaf Area } & \multicolumn{2}{|c|}{ Tree Height } & \multicolumn{2}{|c|}{ Wood Density } & \multicolumn{2}{|c|}{ Specific Leaf Area } & \multicolumn{2}{|c|}{ Tree Height } & \multicolumn{2}{|c|}{ Wood Density } \\
\hline & & & Pearson's $r$ & $p$ & Pearson's $r$ & $p$ & Pearson's $r$ & $p$ & Pearson's $r$ & $p$ & Pearson's $r$ & $p$ & Pearson's $r$ & $p$ \\
\hline \multirow{3}{*}{ Palanan } & 1 & & -0.10 & 0.15 & 0.15 & 0.18 & 0.31 & $<0.05$ & 0.09 & 0.25 & -0.03 & 0.82 & -0.17 & 0.16 \\
\hline & 2 & 0 & 0.26 & $<0.001$ & -0.25 & 0.10 & -0.22 & $<0.01$ & 0.19 & $<0.05$ & 0.31 & 0.06 & -0.23 & $<0.05$ \\
\hline & 3 & 4 & -0.15 & $<0.05$ & 0.18 & 0.22 & 0.21 & 0.07 & 0.21 & $<0.01$ & 0.04 & 0.72 & -0.13 & 0.41 \\
\hline \multirow{2}{*}{ Fushan } & 1 & 1 & -0.30 & $<0.01$ & -0.03 & 0.79 & -0.02 & 0.88 & -0.01 & 0.93 & 0.03 & 0.85 & -0.10 & 0.45 \\
\hline & 2 & 5,0 & -0.22 & $<0.05$ & 0.14 & 0.21 & 0.08 & 0.44 & -0.09 & 0.47 & -0.03 & 0.81 & -0.14 & 0.30 \\
\hline
\end{tabular}

${ }^{\star}$ Hurricane Hugo did occur in September 1989, a category 4 storm that caused limited damage to the forest structure of the Luquillo plot [23,27].

Table 4. Pearson correlation coefficients and their associated probabilities for three functional traits with plot-wide species mortality rates for all stems in the plot $(\geq 1 \mathrm{~cm} \mathrm{dbh})$ and large trees $(\geq 10 \mathrm{~cm}$ dbh) from three cyclonic storm-affected permanent forest dynamics FDPs. Statistically significant correlations are bolded, otherwise the actual probability is given.

\begin{tabular}{|c|c|c|c|c|c|c|c|c|c|c|c|c|c|c|}
\hline \multirow{4}{*}{ Site } & \multirow{4}{*}{$\begin{array}{l}\text { Census } \\
\text { Interval }\end{array}$} & \multirow{4}{*}{$\begin{array}{l}\text { Years Since } \\
\text { Last Major } \\
\text { Cyclonic } \\
\text { Storm }\end{array}$} & \multicolumn{12}{|c|}{ Mortality Rate } \\
\hline & & & \multicolumn{6}{|c|}{ Stems $\geq 1 \mathrm{~cm} \mathrm{dbh}$} & \multicolumn{6}{|c|}{ Stems $\geq 10 \mathrm{~cm} \mathrm{dbh}$} \\
\hline & & & \multicolumn{2}{|c|}{ Specific Leaf Area } & \multicolumn{2}{|c|}{ Tree Height } & \multicolumn{2}{|c|}{ Wood Density } & \multicolumn{2}{|c|}{ Specific Leaf Area } & \multicolumn{2}{|c|}{ Tree Height } & \multicolumn{2}{|c|}{ Wood Density } \\
\hline & & & Pearson's $r$ & $p$ & Pearson's $r$ & $p$ & Pearson's $r$ & $p$ & Pearson's $r$ & $p$ & Pearson's $r$ & $p$ & Pearson's $r$ & $p$ \\
\hline \multirow{6}{*}{$\mathrm{BCI}$} & 1 & & 0.11 & 0.16 & -0.13 & $<0.05$ & -0.39 & $<0.001$ & 0.09 & 0.24 & -0.20 & $<0.01$ & -0.16 & $<0.05$ \\
\hline & 2 & & 0.35 & $<0.001$ & -0.34 & $<0.001$ & -0.29 & $<0.001$ & 0.21 & $<0.01$ & -0.25 & $<0.001$ & -0.23 & $<0.001$ \\
\hline & 3 & & 0.31 & $<0.001$ & -0.34 & $<0.001$ & -0.34 & $<0.001$ & 0.21 & $<0.01$ & -0.29 & $<0.001$ & -0.09 & 0.19 \\
\hline & 4 & & 0.31 & $<0.001$ & -0.33 & $<0.001$ & -0.28 & $<0.001$ & 0.02 & 0.82 & -0.22 & $<0.01$ & -0.16 & $<0.05$ \\
\hline & 5 & & 0.37 & $<0.001$ & -0.24 & $<0.001$ & -0.19 & $<0.01$ & 0.27 & $<0.001$ & -0.22 & $<0.01$ & -0.08 & 0.24 \\
\hline & 6 & & 0.43 & $<0.001$ & -0.23 & $<0.001$ & -0.25 & $<0.001$ & 0.23 & $<0.01$ & -0.21 & $<0.01$ & -0.18 & $<0.01$ \\
\hline \multirow{4}{*}{ Luquillo } & 1 & 2 & 0.34 & $<0.001$ & -0.17 & 0.06 & -0.20 & $<0.05$ & 0.2 & 0.07 & -0.29 & $<0.01$ & 0.22 & $<0.05$ \\
\hline & 2 & $7^{4}$ & 0.55 & $<0.001$ & -0.20 & $<0.001$ & -0.23 & $<0.01$ & 0.11 & 0.34 & -0.19 & 0.09 & 0.22 & $>0.05$ \\
\hline & 3 & 12 & 0.38 & $<0.001$ & -0.23 & $<0.001$ & -0.26 & $<0.01$ & 0.04 & 0.70 & -0.23 & $<0.05$ & 0.04 & 0.72 \\
\hline & 4 & 17 & 0.56 & $<0.001$ & -0.18 & 0.06 & -0.24 & $<0.01$ & 0.21 & 0.06 & -0.27 & $<0.01$ & 0.06 & 0.59 \\
\hline \multirow{3}{*}{ Palanan } & 1 & & 0.23 & $<0.01$ & -0.57 & $<0.01$ & -0.38 & $<0.01$ & 0.09 & 0.25 & -0.03 & 0.82 & -0.17 & 0.16 \\
\hline & 2 & 0 & 0.12 & 0.07 & -0.45 & $<0.01$ & -0.19 & 0.08 & 0.17 & 0.01 & 0.31 & 0.06 & -0.23 & $<0.05$ \\
\hline & 3 & 4 & 0.26 & $<0.01$ & -0.48 & $<0.01$ & -0.32 & $<0.01$ & 0.21 & $<0.01$ & -0.04 & 0.72 & -0.13 & 0.41 \\
\hline \multirow[b]{2}{*}{ Fushan } & 1 & 1 & 0.38 & $<0.001$ & -0.28 & $<0.01$ & -0.24 & $<0.05$ & 0.04 & 0.80 & 0.05 & 0.70 & -0.01 & 0.91 \\
\hline & 2 & 5,0 & 0.37 & $<0.001$ & -0.46 & $<0.001$ & -0.24 & $<0.05$ & 0.09 & 0.48 & -0.10 & 0.45 & 0.02 & 0.89 \\
\hline
\end{tabular}

${ }^{\mathscr{C}}$ Hurricane Hugo did occur in September 1989, a category 4 storm that caused limited damage to the forest structure of the Luquillo plot [23,27]. 


\subsection{Functional Composition}

Community-weighted mean (CWM) trait values for assemblages by quadrat (i.e., at the $20 \mathrm{~m} \times$ $20 \mathrm{~m}$ scale), were most stable for Fushan and differed the most between census intervals at Luquillo (Table 5). Average quadrat CWM values for SLA were substantially lower for BCI, measuring around $12 \mathrm{~cm}^{2} \mathrm{~g}^{-1}$, as opposed to between 14 and $20 \mathrm{~cm}^{2} \mathrm{~g}^{-1}$ for the cyclonic storm-affected FDPs. Average quadrat CWMs for WD also differed, with Fushan measuring below $0.5 \mathrm{~g} \mathrm{~cm}^{-3}$, Palanan and Luquillo measuring between 0.5 and $0.6 \mathrm{~g} \mathrm{~cm}^{-3}$, and BCI measuring approximately $0.6 \mathrm{~g} \mathrm{~cm}^{-3}$. Considerable differences in average quadrat CWMs for tree $\mathrm{H}$ were also found, with tree $\mathrm{H}$ decreasing with increasing cyclonic storm frequency (Table 5).

Table 5. Quadrat averages (mean \pm standard error (SE)) of community-weighted mean (CWM) trait values for specific leaf area (SLA), wood density (WD), and tree height $(\mathrm{H})$, by census for three cyclonic storm-affected permanent forest dynamics FDPs.

\begin{tabular}{|c|c|c|c|c|}
\hline Site & Census & $\begin{array}{l}\text { Avg. Quadrat CWM } \\
\text { SLA }\left(\mathrm{m}^{2} \mathrm{~kg}^{-1}\right)\end{array}$ & $\begin{array}{l}\text { Avg. Quadrat CWM } \\
\text { WD }\left(\mathrm{g} \mathrm{cm}^{-3}\right)\end{array}$ & $\begin{array}{l}\text { Avg. Quadrat CWM H } \\
\text { (m) }\end{array}$ \\
\hline \multirow{7}{*}{$\mathrm{BCI}$} & 1 & $12.10 \pm 0.02$ & $0.594 \pm 0.001$ & $16.7 \pm 0.1$ \\
\hline & 2 & $12.10 \pm 0.02$ & $0.597 \pm 0.001$ & $16.6 \pm 0.1$ \\
\hline & 3 & $12.05 \pm 0.02$ & $0.599 \pm 0.001$ & $16.8 \pm 0.1$ \\
\hline & 4 & $11.95 \pm 0.02$ & $0.603 \pm 0.001$ & $17.1 \pm 0.1$ \\
\hline & 5 & $11.86 \pm 0.02$ & $0.605 \pm 0.001$ & $17.2 \pm 0.1$ \\
\hline & 6 & $11.78 \pm 0.02$ & $0.604 \pm 0.001$ & $17.3 \pm 0.1$ \\
\hline & 7 & $11.73 \pm 0.02$ & $0.603 \pm 0.001$ & $17.4 \pm 0.1$ \\
\hline \multirow{5}{*}{ Luquillo } & 1 & $19.54 \pm 0.02$ & $0.551 \pm 0.003$ & $16.1 \pm 0.2$ \\
\hline & 2 & $19.64 \pm 0.02$ & $0.543 \pm 0.003$ & $15.8 \pm 0.2$ \\
\hline & 3 & $22.10 \pm 0.03$ & $0.534 \pm 0.003$ & $14.8 \pm 0.2$ \\
\hline & 4 & $19.06 \pm 0.02$ & $0.538 \pm 0.003$ & $16.3 \pm 0.2$ \\
\hline & 5 & $17.83 \pm 0.02$ & $0.530 \pm 0.003$ & $17.1 \pm 0.2$ \\
\hline \multirow{4}{*}{ Palanan } & 1 & $14.07 \pm 0.04$ & $0.555 \pm 0.002$ & $16.2 \pm 0.2$ \\
\hline & 2 & $14.02 \pm 0.04$ & $0.554 \pm 0.002$ & $16.4 \pm 0.1$ \\
\hline & 3 & $14.04 \pm 0.03$ & $0.548 \pm 0.001$ & $16.0 \pm 0.1$ \\
\hline & 4 & $14.05 \pm 0.03$ & $0.548 \pm 0.001$ & $16.0 \pm 0.1$ \\
\hline \multirow{3}{*}{ Fushan } & 1 & $17.45 \pm 0.07$ & $0.493 \pm 0.001$ & $15.0 \pm 0.1$ \\
\hline & 2 & $17.69 \pm 0.07$ & $0.493 \pm 0.001$ & $14.6 \pm 0.1$ \\
\hline & 3 & $18.17 \pm 0.07$ & $0.493 \pm 0.001$ & $14.0 \pm 0.1$ \\
\hline
\end{tabular}

We related the change in standardized effect sized for functional divergence $(\triangle \mathrm{SES} F D i v)$ to changes in quadrat biomass (Figure 5). Recall that at the plot level, BCI and Luquillo had consistent declines in biomass, while the trend for biomass production was positive, negative and positive for the three census intervals at Palanan, and positive for both census intervals for Fushan (Table 2). First, looking at the non-cyclonic storm affected forest, BCI (Figure 5e), 48\% of quadrats had positive (>0) $\triangle$ SES FDiv values in the first census interval, and census intervals $2-6$ had $43 \%, 38 \%, 45 \%, 44 \%$ and $43 \%$ of quadrats with positive $\triangle$ SES FDiv values. Luquillo registered positive $\triangle$ SES FDiv values for $63 \%, 46 \%, 46 \%$ and $68 \%$ of quadrats in census intervals one through four, respectively (Figure $5 \mathrm{~d}$ ). Of the $46 \%$ of quadrats that had positive $\triangle$ SES FDiv values in census interval 2, 43\% (79 of the 182 quadrats) continued toward positive $\triangle$ SES FDiv, so there was some functional turnover for Luquillo between census intervals two and three. The $\triangle$ SES FDiv values for Palanan were stable (Figure 5c), but fluctuated in magnitude, being positive $47 \%, 48 \%$, and $47 \%$ of the time for intervals one through three, respectively. At Palanan, there was also turnover among the quadrats with positive $\triangle$ SES FDiv values, with $49 \%$ (93 of the 190 quadrats) shared between census intervals 1 and 2 and $45 \%$ (86 of the 191 quadrats) shared between intervals 2 and 3. Lastly, the Fushan FDP had positive $\triangle$ SES FDiv values for $74 \%$ of quadrats for the first census interval and $62 \%$ of quadrats for the second (Figure $5 \mathrm{~b}$ ). 

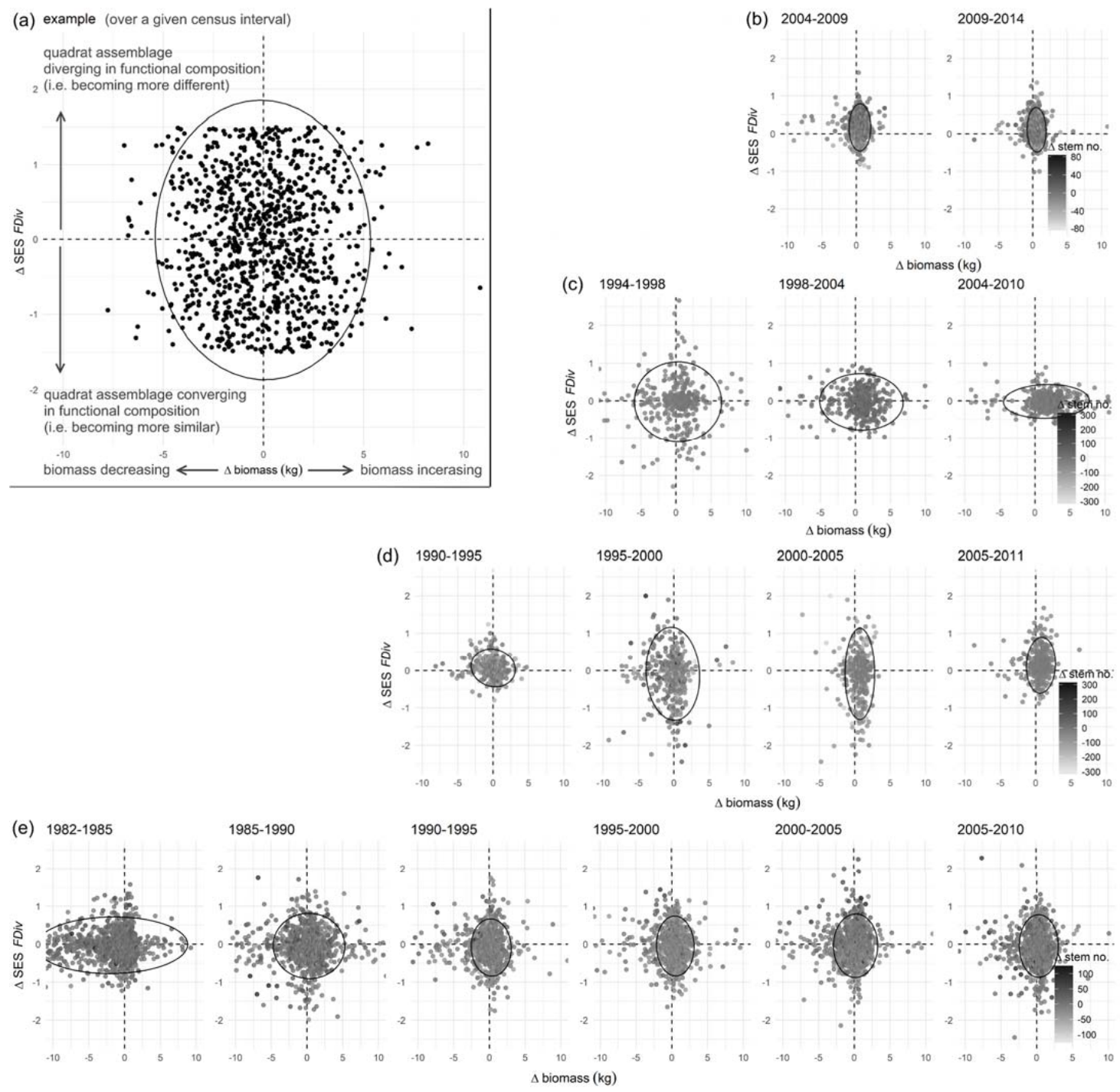

Figure 5. The change in quadrat biomass ( $\Delta$ biomass) in kilograms plotted against the change in the standardized effect size of Functional Divergence ( $\triangle$ SES FDiv) of the quadrat species assemblage over 5-year census intervals for the 4 cyclonic storm-affected permanent forest dynamics FDPs: (b) Fushan, Taiwan; (c) Palanan, Philippines; (d) Luquillo, Puerto Rico; and (e) Barro Colorado Island (BCI), Panama. 95\% Confidence ellipses shown. The example (a) shows a perfectly uniform relationship between $\Delta$ biomass and $\triangle$ SES FDiv. Ellipses wider than tall illustrate greater community change in biomass than functional divergence over a given ca. 5-year census interval, while ellipses taller than wide illustrate the opposite. Note that four major cyclonic storms have affected the Fushan plot (b) in two census intervals-Typhoons Area (2004), Jangmi (2008), Sinlaku (2008), and Soulik (2013); Three storms have affected the Palanan plot (c) over three census intervals-Typhoons Zeb (1998), Imbudo (2003), and Mitag (2007); And two major storms have occurred over four census intervals for the Luquillo plot (d)-Hurricanes Hugo (1989) and Georges (1998).

Across all FDPs, rarely did the $\triangle$ SES FDiv of a quadrat assemble exceed \pm 2 . Ellipses in Figure 5 represent $95 \%$ confidence interval bounds for the point clouds. Ellipses that are wider than long illustrate a greater variability in quadrat biomass changes than in quadrat functional divergence, whereas ellipses that are longer than wide illustrate greater changes in functional divergence of quadrat species assemblages with little change in quadrat biomass (Figure 5a). Circular confidence ellipses show equal degrees of changes in quadrat functional divergence and quadrat biomass (e.g., Figure 5a). The middle two census intervals for Luquillo (Figure 5d) and the first census interval for Palanan 
(Figure 5c) showed a spread in $\triangle$ SES FDiv without much change in the quadrat biomass flux. A greater percentage of quadrats lost biomass in the second interval at Luquillo, due to the impact of Hurricane Georges in 1998. A similar pattern is visible in functional divergence at Palanan from 1994-1998 when Typhoon Zeb affected the plot. For Fushan, the quadrats show considerably less variation in $\triangle S E S$ FDiv, despite having at least double the hurricane frequency (Figure 5b). For all four FDPs, $\triangle$ SES FDiv across census intervals tended to be greatest in quadrats with little biomass fluctuation.

\section{Discussion}

Using tree census data from four large, permanent FDPs with different disturbance regimes that are primarily attributed to cyclonic storm frequency (Table 1), we have shown differences in forest demographic (Figures 2-4, Table 2) and functional responses at the small patch scale $(20 \times 20 \mathrm{~m}$ quadrats) (Figure 5, Table 5) to large cyclonic storms. BCI did experience some moderate winds, but not the sustained and damaging cyclonic storms of the other three FDPs; therefore, at BCI forest dynamics can be attributed to gap-phase dynamics related to tree senescence and fall. Luquillo, Puerto Rico, was the most demographically dynamic forest and demonstrated the most functional variation in community composition. BCI, Panama, was the most dynamic in terms of stem growth increment and biomass dynamics, probably because of the more fertile soil conditions and other ecosystem factors that differ between montane island forests and lowland continental forests (e.g., nutrient cycling, hydrology). Of the directly cyclone-impacted plots, Palanan, Philippines, was less dynamic in population abundances, but about as functionally dynamic as Luquillo. Fushan, Taiwan, was neither very dynamic in population fluctuations of species nor in functional responses to cyclonic storms, despite being affected by them most-frequently.

Within an ecological disturbance framework [66,67] and employing the definition of forest resistance to the cyclonic storm as the degree to which forest demographic and functional composition remain unchanged by disturbance, we show the Fushan FDP to be highly resistant to cyclonic storms. BCI also exhibits a relatively high degree of forest stability in the absence of cyclonic storms (Figure 5, Table 5). Fushan and BCI are comparable in their relatively low degree of demographic and functional variability across census intervals but differ considerably in the type of tropical forest they contain, which is evident in the degree of biomass flux at the hectare (Table 2) and quadrat (Figure 5) scales. Luquillo and Palanan are both more dynamic in forest demographics and their functional responses, with the functional divergence in relation to cyclonic storms persisting for longer at Luquillo after a storm. The forest at BCI is a typical neotropical lowland forest with an average canopy height of $30 \mathrm{~m}$ [68,69], but the canopy height at Fushan is 15-20 m in the valleys and flat areas and 5-10 $\mathrm{m}$ on the ridges [41]. Luquillo and Palanan possess an intermediate canopy height of about $20 \mathrm{~m} \mathrm{[13].}$ Such differences in canopy height are driven by the constant pruning of canopy of the forests by cyclonic wind disturbance [70]. Furthermore, Luquillo, Fushan, and Palanan all lack canopy emergent trees, which is undoubtedly a forest-wide result of recurrent cyclonic storms $[13,41,70]$.

This clear relationship of decreasing canopy height and storm frequency invokes the idea of disturbance legacy effects and the idea of ecological memory sensu Johnstone et al. [71]. Indeed, there is an underappreciated level of evolution at the species level and adaption at the individual level to environments that experience intense wind. Griffith et al. [72] showed that palms from cyclonic storm-prone provenance have an order of magnitude of lower percent mortality than those from non-cyclonic storm-prone provenances in the living collections of Montgomery Botanical Garden, Florida following Hurricane Wilma in 2005. A cyclonic storm-resistant palm, Presotea acuminata var. montana (Graham) A.J. Hend. and Galeano is the most abundant species at Luquillo, accounting for a third of the stems in the plot. Furthermore, the dominant canopy tree at Luquillo, Dacryodes excelsa Vahl forms complex root unions, which help collectively stabilize individuals during high winds and help maintain a regeneration foothold in the community [73]. Trees at Fushan maintain a smaller stature, because those that are exposed above the canopy or grow in gap habitats are frequently damaged by cyclonic storms and incur higher rates of mortality [74]. This disturbance effect operates more strongly 
and consistently at Fushan and Palanan than at Luquillo and has no effect on the forest structure of $\mathrm{BCI}$, hence the occurrence of canopy emergents, oftentimes extending above the forest canopy layer by $10 \mathrm{~m}$ or more [69]. Such adaptations to wind disturbance at the individual and species level, and the ability of trees to adapt to and persist under changing disturbance regimes, have implications for ecosystem processes (e.g., carbon and nutrient cycling) and the fate of future tropical forests.

4.1. Do Forests That Have Storm Recurrence Intervals That Coincide with the Time to Reproductive Maturity of Tropical Trees Show More Variable Demographics Than Forests with More Frequent or No Cyclonic Storms?

We have shown that population growth and mortality rates of species are more temporally variable and dynamic at Luquillo than at BCI, Palanan or Fushan. Species richness of the Luquillo FDP has declined steadily over time [25] as pioneer type species died with canopy closure and forest recovery from hurricane damage. Disturbance theory [1,75,76] predicts species richness to be considerably higher at Luquillo than either Fushan or BCI. However, there are other factors that govern diversity at Luquillo. Island Biogeography Theory predicts a lower species diversity as Puerto Rico is a mid-sized continental island a large distance from the nearest land mass. Taiwan is a similarly sized island, but considerably closer to its nearest continent. Regardless, the key point is that we have shown the populations of species at Luquillo to be considerably more dynamic than either the non-cyclonic storm-affected forest of BCI or the frequently cyclonic storm-visited forests of Palanan and Fushan.

This could be one possible mechanism by which cyclonic storms may facilitate the degree of diversity in forests up to a point (i.e., a unimodal distribution); disturbance acts as the driver of population fluctuations, through the alteration of the abiotic environment and a direct effect on individual performance, thereby increasing temporal environmental heterogeneity and facilitating species coexistence. The degree to which disturbance drives population dynamics depends on the collective state of the populations (i.e., metapopulation or community), which happens to be most developed at intermediate levels of disturbance, irrespective of diversity. The diversity maintenance effect of intermediate levels of disturbance [75] is a consequence of the greater effect of a disturbance at intermediate recurrence intervals, which certainly interacts with other drivers of population and community dynamics (e.g., historical contingency effects, metacommunity dynamics, etc.), and the diversity of plant life-history strategies found in tropical forests.

4.2. Do Forests That Have Storm Recurrence Intervals That Coincide with the Time to Reproductive Maturity of Tropical Trees Show Greater Changes in Functional Community Composition (i.e., More Variation in Species Life-History Strategy per Unit Area over Time) Than Forests with More Frequent or No Cyclonic Storms?

The functional trait-demographic rate correlations (Tables 3 and 4) are both congruent with previous studies [46,47] and confirm a previous finding by Wright et al. [48] that relationships strengthen when including all stems (those $\geq 1 \mathrm{~cm} \mathrm{dbh}$, as opposed to limiting the analysis to large trees $\geq 10 \mathrm{~cm} \mathrm{dbh).} \mathrm{In} \mathrm{cyclonic-storm} \mathrm{affected} \mathrm{forests,} \mathrm{tree} \mathrm{height} \mathrm{was} \mathrm{a} \mathrm{poor} \mathrm{correlate} \mathrm{for} \mathrm{population}$ growth rates (Table 3), because of the interchanging dynamics of tall canopy trees and understory shrubs. Depending on the structure of the forest and its patch dynamism, the population growth of trees or shrubs may be greater. However, tree $H$ was negatively correlated with mortality rates (Table 4), except for large trees at Palanan and Fushan. For functional trait-population growth rate relationships, there exists a tradeoff between WD and SLA. In census intervals where cyclonic storm damage occurred, WD was positively correlated with the community-wide intrinsic rate of population growth, yet in census intervals where the forest was recovering from storm damage, SLA was the strongest correlate. This relates species life-history strategies to the relative strength of cyclonic storm damage verses light-dependent processes governing population dynamics [6,7]. Specifically, during storm intervals the populations of dense wooded species grow faster than pioneer species with less-dense wood, whereas following storms the opposite is true. In a world with increasing cyclonic storm occurrence, dense wooded, slow-growing, shade-tolerant species may have increasingly dynamic population fluctuations. 
The cyclonic storm return interval is important because it determines the successional composition of adult trees that are impacted by the disturbance. Namely, at shorter intervals, species with fast population growth rates that typically have high SLA or other acquisitive, pioneer-type functional traits tend to be more negatively affected by storms (i.e., incur greater degrees of stem damage and mortality), decreasing the intrinsic rates of population growth of those species to a greater degree than late-successional species. Conversely, at longer intervals, few pioneer species comprise the community of adult trees, and late-successional species are more damaged, subsequently decreasing the population growth rates of those species to a greater degree. Pioneer species can, then, readily colonize the canopy in the high-light environment of a cyclone-disturbed forest and populations can grow rapidly.

The correlations of functional traits and population growth rates of species (Table 3) tended to weaken or become non-significant over census intervals in between cyclonic storms occurrence (e.g., Luquillo census interval 2 and Palanan census interval 1), illustrating not only the widespread damaging effects of the storms, but also the interplay in forest successional status and individual life-history strategies as they relate to storm intensity, recurrence interval, and the composition of species in each plot. These results support a growing need in the discipline of functional plant ecology to delve deeper into our understanding of individual performance and the underlying factors influencing functional trait variability, or lack thereof $[77,78]$. We show mixed evidence for the applicability of functional traits in explaining population and community dynamics in response to disturbance, using trait data collected at the species level (Tables 3 and 4). Notably, relationships were weaker for population growth than mortality rates (Table 4), likely owing to the distinct biological processes, and a greater degree of demographic variability, in stem recruitment versus stem mortality. Indeed, the short-term damage of cyclonic storms appears indiscriminate (Figure 1), yet the effects of the disturbance on the population dynamics of species and the community (e.g., ecological selection processes, delayed mortality, recruitment) take time to register in forest dynamics data $[16,19]$. As hypothesized, all three functional traits correlated to some degree with the variation in stem mortality (Table 4). Luquillo had some of the strongest Pearson correlation coefficients for SLA, and Palanan had the strongest correlations for tree $\mathrm{H}$. In a world with increasing cyclonic storm occurrence, this implies possible selection against species with large or cheaply-constructed leaves (high SLA), as illustrated by forest dynamics at Luquillo, and trees with tall stature, as illustrated by the dynamics at Palanan.

Among BCI, Luquillo, Palanan, and Fushan, Fushan had the most-stable functional communities. For example, the community-weighted mean value for $\mathrm{WD}$ at the quadrat $(20 \times 20 \mathrm{~m})$ scale remained unchanged over a decade (Table 5). SLA and tree H mirrored this dynamic. Similarly, Fushan had the least functionally divergent assemblages among quadrats (Figure 5). It was difficult to account for differences in forest biomass distribution among FDPs. Biomass fluctuations for quadrats at BCI were six to seven times greater than those at Fushan, likely because of the difference in tree size and effect of a large treefalls at BCI. However, when comparing quadrats within $\pm 10 \mathrm{~kg}_{\text {quadrat }}{ }^{-1}$ biomass change, the change in standardized effect size for functional divergence rarely exceed \pm 1 for Fushan, \pm 2 for BCI, and occasionally exceeded \pm 2 for Palanan and Luquillo, notably when the FDPs were recently affected by cyclonic storms (Figure 5). Thus, in a world with increasing cyclonic storm occurrence, community assemblages could become increasingly mixed with a wider range of tree life-histories, or functionally divergent. However, this is largely context dependent, and depends on the individual population dynamics of tree species in the community, and species immigration and extinction-demographic responses which are either directly or indirectly affected by disturbance. Our results also show increasing similarity in certain assemblages.

At Luquillo, Hurricane Georges (1998) increased the variability in the functional divergence of quadrat assemblages, which can be most clearly seen in census intervals 2 and 3. Similarly, at Palanan during census interval 1, the functional divergence variation among quadrats increased because of Typhoon Zeb (Figure 5). This means that quadrats became either more similar or more different in their functional composition when struck by the category 2 storm. At Luquillo, this is likely due to the 
differential susceptibilities of species $[18,20]$ and how they are preferentially sorted in space across the plot by past land use $[25,79]$. Hurricane Georges interacted with the land-use legacies, forcing communities to become more different, via functional divergence, which was primarily driven by a proliferation of understory shrubs [25]. At Palanan, typhoons interact with the plot topography, mainly windward vs. leeward slopes, where mortality and recruitment are higher during and after cyclonic storm disturbance [40]. At BCI and Fushan, such events are limited to gap areas and are more spatially and temporally variable because of the lesser degree of landscape-scale canopy alteration via disturbance. This limits the functional divergence of those FDPs to be less variable, thus making the communities relatively more stable.

Our result about cyclonic storms increasing community functional divergence aligns with previous research on the functional diversity of Luquillo, which has shown a variety of functional traits to be phylogenetically overdispersed [49] when compared to BCI and other forests [80]. Together these confirm that the functional trait diversity expressed in the community arises from a more-distantly related assemblage of angiosperms than in other forests such as BCI, which we contend is related to disturbance-effects on the community, chiefly a greater persistence of pioneer species. Truly, over a given timespan, forests that have storm recurrence intervals at timescales closer to the average tree lifespan show greater changes in functional community composition than forests with more frequent or no cyclonic storms. The interval of storm recurrence is a significant factor, in that at shorter intervals the persistence of pioneer species is decreased, as shown in the example of the Fushan plot, thereby decreasing the degree of functional trait diversity in the community. At longer intervals, late-successional species can dominate, shifting functional composition toward lower SLA and higher WD, with pioneer species persisting primarily in forest gaps. Therefore, a world with increasing cyclonic storm occurrence should permit for the co-existence of a wide range of ecological strategies within tropical forests, and possibly increase the functional diversity of forests experiencing new, or more frequent cyclonic storms, potentially increasing forest dynamism.

\section{Conclusions}

We find some support for the understanding that intermediate levels of cyclonic wind disturbance facilitate demographic variability in tropical forest trees. This demographic variability leads to more temporally variable functional assemblages of species and allows for a more dynamic coexistence of life-histories over time. Although there are undoubtedly other ecological forces at work in these forests (e.g., biogeographic effects), these results support the idea that tropical forest trees exhibit a wide range of life-history and survival strategies that are tuned to disturbance regimes rather than individual disturbance events $[1,8,24,64,68,81]$. We contend that it is this ecological regulation of expressed life-histories that leads to the demographic and functional trait differences in the tree communities at these permanent study sites. However, the limited number of sites (4) is a clear limitation to the results of this study and the results may not be completely representative of the range of forest responses to cyclonic windstorm disturbance regimes.

Additionally, we lack damage data for trees at the individual level, along with a suite of other, more-mechanical functional traits that are well suited for addressing tree resistance to wind damage at the individual level, such as factors of safety [82], or moments of inertia and the specific ways in which wind interacts [83] with each tree in each plot. Future work could potentially focus on how individual responses and susceptibility to storm-related damage connect to the population and community-level trends of this study. Given the propensity for cyclonic wind disturbances to increase in frequency and intensity $[84,85]$ as global climate change continues, we expect cyclonic wind disturbances to continue to shape the world's forests and their dynamics [81], with selection pressure towards the extremes in functional variability in forest communities with increasing cyclonic storm frequency. In a world with increasing cyclonic storm occurrence, the degree to which increasing demographic and functional dynamism in forests contributes to changes in ecosystem processes, such as forest carbon storage, will vary and depend on how storms separately and collective affect forests. 
Supplementary Materials: The following are available online at http://www.mdpi.com/1999-4907/9/7/404/s1, Supplementary File S1: Population change models.

Author Contributions: J.A.H. and J.K.Z. conceived the idea; S.J.D. generated funding and oversaw all data collection. J.K.Z., J.T., M.U., N.G.S., R.C., S.H., I.F.S., C.-H.C.-Y., S.-H.S., P.O., L.R., C.C.M. and S.Y. collected the data. J.A.H., N.G.S., and D.J.J. analyzed the data; R.C. contributed analysis tools; J.A.H. wrote the paper. All authors contributed intellectually and edited manuscript drafts.

Funding: Funding to support these FDPs has been provided by the US National Science Foundation (BSR-8811902, DEB-9411973, DEB-9705814, DEB-0080538, DEB-0218039, DEB-0620910, and DEB-1516066), the John D., and Catherine T. MacArthur Foundation, the UDSA International Institute of Tropical Forestry, the Council of Agriculture and the Ministry of Science and Technology of Taiwan, the University of the Philippines, the Department of Science and Technology-Philippine Council for Agriculture, the Forest Foundation Philippines, the Diliman Science Research Foundation, and the Smithsonian Institute, specifically the Smithsonian Tropical Research Institute and the Smithsonian Institution Global Earth Observatories. Stuart J. Davies, of CTFS Forest-GEO, received funding from the Next Generation Ecosystem Experiment (NGEE-) Tropics project.

Acknowledgments: We thank the four anonymous reviewers of this manuscript for their comments. This work was completed in conjunction with the CTFS network and greatly benefited from the 2016 and 2017 workshops in Jianfengling, China, and Luquillo, Puerto Rico. We thank Patrick Baker and Sean McMahon for their service as workshop group leaders, and the support staff of CTFS. We acknowledge Nicholas Brokaw and Ervan Rutishauser for comments which improved the manuscript. The data from the FDPs are the result of the collective effort of countless individuals, who usually work on a volunteer or minimal compensation basis-we are grateful for their hard work.

Conflicts of Interest: The authors declare no conflicts of interest.

\section{References}

1. Turner, M.G.; Dale, V.H. Comparing large, infrequent disturbances: What have we learned? Ecosystems 1998, 1, 493-496. [CrossRef]

2. Lugo, A.E.; Scatena, F.N. Background and catastrophic tree mortality in tropical moist, wet, and rain forests. Biotropica 1996, 28, 585-599. [CrossRef]

3. Zimmerman, J.K.; Willig, M.R.; Walker, L.R.; Silver, W.L. Introduction: disturbance and Caribbean ecosystems. Biotropica 1996, 28, 414-423. [CrossRef]

4. Shen, Y.; Santiago, L.S.; Ma, L.; Lin, G.-J.; Lian, J.-Y.; Cao, H.-L.; Ye, W.-H. Forest dynamics of a subtropical monsoon forest in Dinghushan, China: Recruitment, mortality and the pace of community change. J. Trop. Ecol. 2013, 29, 131-145. [CrossRef]

5. Heartsill Scalley, T.; Scatena, F.N.; Lugo, A.E.; Moya, S.; Estrada Ruiz, C.R. Changes in structure, composition, and nutrients during $15 \mathrm{yr}$ of hurricane-induced succession in a subtropical wet forest in Puerto Rico. Biotropica 2010, 42, 455-463. [CrossRef]

6. Everham, E.M.; Brokaw, N.V. Forest damage and recovery from catastrophic wind. Bot. Rev. 1996, 62, $113-185$. [CrossRef]

7. Chambers, J.Q.; Fisher, J.I.; Zeng, H.; Chapman, E.L.; Baker, D.B.; Hurtt, G.C. Hurricane Katrina's carbon footprint on U.S. Gulf Coast forests. Science 2007, 318, 1107. [CrossRef] [PubMed]

8. Vandermeer, J.H.; Boucher, D.H.; de la Cerda, I.G.; Perfecto, I. Growth and development of the thinning canopy in a post-hurricane tropical rain forest in Nicaragua. For. Ecol. Manag. 2001, 148, 221-242. [CrossRef]

9. Brokaw, N.; Zimmerman, J.K.; Willig, M.R.; Camilo, G.R.; Covich, A.P.; Crowl, T.A.; Fetcher, N.; Haines, B.L.; Lodge, D.J.; Lugo, A.E.; et al. Response to disturbance. In A Caribbean Forest Tapestry: The Multidimensional Nature of Disturbance and Response; Brokaw, N., Crowl, T.A., Lugo, A.E., McDowell, W.H., Scatena, F.N., Waide, R.B., Willig, M.R., Eds.; Oxford University Press: New York, NY, USA, 2012; pp. 201-271.

10. Walker, L.R. Timing of post-hurricane tree mortality in Puerto Rico. J. Trop. Ecol. 1995, 11, 315-320. [CrossRef]

11. Van Bloem, S.J.; Murphy, P.G.; Lugo, A.E. A link between hurricane-induced tree sprouting, high stem density and short canopy in tropical dry forest. Tree Physiol. 2007, 27, 475-480. [CrossRef] [PubMed]

12. Bellingham, P.; Tanner, E.; Healey, J. Damage and responsiveness of Jamaican montane tree species after disturbance by a hurricane. Ecology 1995, 76, 2562-2580. [CrossRef]

13. Brokaw, N.V.; Grear, J.S. Forest structure before and after hurricane Hugo at three elevations in the Luquillo mountains, Puerto Rico. Biotropica 1991, 23, 386-392. [CrossRef] 
14. Zimmerman, J.K.; Comita, L.S.; Thompson, J.; Uriarte, M.; Brokaw, N. Patch dynamics and community metastability of a subtropical forest: Compound effects of natural disturbance and human land use. Landsc. Ecol. 2010, 25, 1099-1111. [CrossRef]

15. Luke, D.; McLaren, K.; Wilson, B. Modeling hurricane exposure in a Caribbean lower montane tropical wet forest: The effects of frequent, intermediate disturbances and topography on forest structural dynamics and composition. Ecosystems 2016, 19, 1178-1195. [CrossRef]

16. Lugo, A.E. Visible and invisible effects of hurricanes on forest ecosystems: An international review. Austral Ecol. 2008, 33, 368-398. [CrossRef]

17. Webb, E.L.; Bult, M.; Fa'aumu, S.; Webb, R.C.; Tualaulelei, A.; Carrasco, L.R. Factors affecting tropical tree damage and survival after catastrophic wind disturbance. Biotropica 2014, 46, 32-41. [CrossRef]

18. Zimmerman, J.K.; Everham, E.M., III; Waide, R.B.; Lodge, D.J.; Taylor, C.M.; Brokaw, N.V. Responses of tree species to hurricane winds in subtropical wet forest in Puerto Rico: Implications for tropical tree life histories. J. Ecol. 1994, 82, 911-922. [CrossRef]

19. Uriarte, M.; Canham, C.D.; Thompson, J.; Zimmerman, J.K. A neighborhood analysis of tree growth and survival in a hurricane-driven tropical forest. Ecol. Monogr. 2004, 74, 591-614. [CrossRef]

20. Tanner, E.V.J.; Rodriguez-Sanchez, F.; Healey, J.R.; Holdaway, R.J.; Bellingham, P.J. Long-term hurricane damage effects on tropical forest tree growth and mortality. Ecology 2014, 95, 2974-2983. [CrossRef]

21. Monoy, C.C.; Tomlinson, K.W.; Iida, Y.; Swenson, N.G.; Slik, J.F. Temporal changes in tree species and trait composition in a cyclone-prone pacific dipterocarp forest. Ecosystems 2016, 19, 1013-1022. [CrossRef]

22. Tanner, E.V.J.; Kapos, V. Leaf structure of Jamaican upper montane rain-forest trees. Biotropica 1982, 14, 16-24. [CrossRef]

23. Gunderson, L.H. Ecological resilience-In theory and application. Annu. Rev. Ecol. Syst. 2000, 31, 425-439. [CrossRef]

24. Scatena, F.N.; Blanco, J.F.; Beard, K.H.; Waide, R.B.; Lugo, A.E.; Brokaw, N.; Silver, W.L.; Haines, B.L.; Zimmerman, J.K. Disturbance regime. In A Caribbean Forest Tapestry: The Multidimensional Nature of Disturbance and Response; Oxford University Press: New York, NY, USA, 2012; pp. 164-200.

25. Hogan, J.A.; Zimmerman, J.K.; Thompson, J.; Nytch, C.J.; Uriarte, M. The interaction of land-use legacies and hurricane disturbance in subtropical wet forest: Twenty-one years of change. Ecosphere 2016, 7. [CrossRef]

26. Paine, R.T.; Tegner, M.J.; Johnson, E.A. Compounded perturbations yield ecological surprises. Ecosystems 1998, 1, 535-545. [CrossRef]

27. Buma, B.; Wessman, C. Disturbance interactions can impact resilience mechanisms of forests. Ecosphere 2011, 2, 1-13. [CrossRef]

28. Lugo, A.E.; Applefield, M.; Pool, D.J.; McDonald, R.B. The impact of hurricane David on the forests of Dominica. Can. J. For. Res. 1983, 13, 201-211. [CrossRef]

29. Uriarte, M.; Canham, C.D.; Thompson, J.; Zimmerman, J.K.; Murphy, L.; Sabat, A.M.; Fetcher, N.; Haines, B.L. Natural disturbance and human land use as determinants of tropical forest dynamics: Results from a forest simulator. Ecol. Monogr. 2009, 79, 423-443. [CrossRef]

30. Tanner, E.; Bellingham, P. Less diverse forest is more resistant to hurricane disturbance: Evidence from montane rain forests in Jamaica. J. Ecol. 2006, 94, 1003-1010. [CrossRef]

31. Ostertag, R.; Silver, W.L.; Lugo, A.E. Factors affecting mortality and resistance to damage following hurricanes in a rehabilitated subtropical moist forest. Biotropica 2005, 37, 16-24. [CrossRef]

32. Tanner, E.; Kapos, V.; Healey, J. Hurricane effects on forest ecosystems in the Caribbean. Biotropica 1991, 23, 513-521. [CrossRef]

33. Shaw, W. Tropical cyclones: Determinants of pattern and structure in New Zealand's indigenous forests. Pac. Sci. 1983, 37, 405-414.

34. Canham, C.D.; Loucks, O.L. Catastrophic windthrow in the presettlement forests of Wisconsin. Ecology 1984, 65, 803-809. [CrossRef]

35. Vandermeer, J.; Granzow De La Cerda, I.; Perfecto, I.; Boucher, D.; Ruiz, J.; Kaufmann, A. Multiple basins of attraction in a tropical forest: Evidence for nonequilibrium community structure. Ecology 2004, 85, 575-579. [CrossRef]

36. Terborgh, J.; Flores, C.N.; Mueller, P.; Davenport, L. Estimating the ages of successional stand of tropical trees from growth increments. J. Trop. Ecol. 1997, 14, 833-856. [CrossRef] 
37. Condit, R. Tropical Forest Census FDPs: Methods and Results from Barro Colorado Island, Panama and a Comparison with Other FDPs; Springer: Berlin, Germany, 1998.

38. Anderson-Teixeira, K.J.; Davies, S.J.; Bennett, A.C.; Gonzalez-Akre, E.B.; Muller-Landau, H.C.; Joseph Wright, S.; Abu Salim, K.; Almeyda Zambrano, A.M.; Alonso, A.; Baltzer, J.L. CTFS-ForestGeo: A worldwide network monitoring forests in an era of global change. Glob. Chang. Biol. 2015, 21, 528-549. [CrossRef] [PubMed]

39. Condit, R.; Lao, S.; Pérez, R.; Dolins, S.B.; Foster, R.; Hubbell, S. Barro Colorado Forest Census Plot Data (Version 2012); Center for Tropical Forest Science Databases: Washington, DC, USA, 2012. [CrossRef]

40. Zimmerman, J.K.; Thompson, J. Census of Species, Diameter and Location at the Luquillo Forest Dynamics Plot (LFDP); Luquillo LTER: San Juan, Puerto Rico, 2011.

41. Yap, S.L.; Davies, S.J.; Condit, R. Dynamic response of a Philippine dipterocarp forest to typhoon disturbance. J. Veg. Sci. 2016, 27, 133-143. [CrossRef]

42. Su, S.-H.; Chang-Yang, C.; Lu, C.; Tsui, C.; Lin, T.; Lin, C.; Chiou, W.; Kuan, L.; Chen, Z.; Hsieh, C. Fushan Subtropical Forest Dynamics Plot: Tree Species Characteristics and Distribution Patterns; Taiwan Forestry Research Institute: Taipei City, Taiwan, 2007.

43. Soil Survey Staff. Order 1 Soil Survey of the Luquillo Long-Term Ecological Research Grid, Puerto Rico; USDA, Natural Resources Conservation Service Lincoln: Lincoln, NE, USA, 1995.

44. Co, L.L.; Lagunzad, D.A.; LaFrankie, J.V.; Bartolome, N.A.; Molina, J.E.; Yap, S.L.; Garcia, H.G.; Bautista, J.P.; Gumpal, E.C.; Araño, R.R.; et al. Palanan forest dynamics plot, Philippines. In Tropical Forest Diversity and Dynamism: Findings from a Large-Scale Plot Network; Losos, E.C., Leigh, E.G., Eds.; University of Chicago Press: Chicago, IL, USA, 2004.

45. Dietrich, W.; Windsor, D.; Dunne, T. Geology, Climate, and Hydrology of Barro Colorado Island [Tropical Forest, Panama]; Smithsonian Institutional Press: Washington, DC, USA, 1982.

46. Díaz, S.; Kattge, J.; Cornelissen, J.H.; Wright, I.J.; Lavorel, S.; Dray, S.; Reu, B.; Kleyer, M.; Wirth, C.; Prentice, I.C. The global spectrum of plant form and function. Nature 2016, 529, 167. [CrossRef] [PubMed]

47. Poorter, L.; Wright, S.J.; Paz, H.; Ackerly, D.D.; Condit, R.; Ibarra-Manríquez, G.; Harms, K.E.; Licona, J.; Martinez-Ramos, M.; Mazer, S. Are functional traits good predictors of demographic rates? Evidence from five neotropical forests. Ecology 2008, 89, 1908-1920. [CrossRef] [PubMed]

48. Wright, S.J.; Kitajima, K.; Kraft, N.J.; Reich, P.B.; Wright, I.J.; Bunker, D.E.; Condit, R.; Dalling, J.W.; Davies, S.J.; Díaz, S. Functional traits and the growth-mortality trade-off in tropical trees. Ecology 2010, 91, 3664-3674. [CrossRef] [PubMed]

49. Swenson, N.G.; Stegen, J.C.; Davies, S.J.; Erickson, D.L.; Forero-Montaña, J.; Hurlbert, A.H.; Kress, W.J.; Thompson, J.; Uriarte, M.; Wright, S.J. Temporal turnover in the composition of tropical tree communities: Functional determinism and phylogenetic stochasticity. Ecology 2012, 93, 490-499. [CrossRef] [PubMed]

50. Lasky, J.R.; Sun, I.; Su, S.H.; Chen, Z.S.; Keitt, T.H. Trait-mediated effects of environmental filtering on tree community dynamics. J. Ecol. 2013, 101, 722-733. [CrossRef]

51. Iida, Y.; Kohyama, T.S.; Swenson, N.G.; Su, S.H.; Chen, C.T.; Chiang, J.M.; Sun, I. Linking functional traits and demographic rates in a subtropical tree community: The importance of size dependency. J. Ecol. 2014, 102, 641-650. [CrossRef]

52. Knapp, K.R.; Kruk, M.C.; Levinson, D.H.; Diamond, H.J.; Neumann, C.J. The international best track archive for climate stewardship (IBTrACS) unifying tropical cyclone data. Bull. Am. Meteorol. Soc. 2010, 91, 363-376. [CrossRef]

53. Moyer, A.C.; Evans, J.L.; Powell, M. Comparison of observed gale radius statistics. Meterol. Atmos. Phys. 2007, 97, 41-55. [CrossRef]

54. Hsu, S.; Babin, A. Estimating the radius of maximum wind via satellite during Hurricane Lili (2002) over the Gulf of Mexico. Natl. Weather Assoc. Electron. J. 2005, 6, 1-6.

55. Vandermeer, J.H.; Goldberg, D.E. Population Ecology: First Principles; Princeton University Press: Princeton, NJ, USA, 2013.

56. Chisholm, R.A.; Condit, R.; Rahman, K.A.; Baker, P.J.; Bunyavejchewin, S.; Chen, Y.Y.; Chuyong, G.; Dattaraja, H.; Davies, S.; Ewango, C.E. Temporal variability of forest communities: Empirical estimates of population change in 4000 tree species. Ecol. Lett. 2014, 17, 855-865. [CrossRef] [PubMed]

57. Lugo, A.E. Effects and outcomes of caribbean hurricanes in a climate change scenario. Sci. Total Environ. 2000, 262, 243-251. [CrossRef] 
58. Chave, J.; Réjou-Méchain, M.; Búrquez, A.; Chidumayo, E.; Colgan, M.S.; Delitti, W.B.; Duque, A.; Eid, T.; Fearnside, P.M.; Goodman, R.C. Improved allometric models to estimate the aboveground biomass of tropical trees. Glob. Chang. Biol. 2014, 20, 3177-3190. [CrossRef] [PubMed]

59. Brokaw, N.V. Gap-phase regeneration in a tropical forest. Ecology 1985, 66, 682-687. [CrossRef]

60. Brokaw, N.V. The definition of treefall gap and its effect on measures of forest dynamics. Biotropica 1982, 14, 158-160. [CrossRef]

61. Villéger, S.; Mason, N.W.; Mouillot, D. New multidimensional functional diversity indices for a multifaceted framework in functional ecology. Ecology 2008, 89, 2290-2301. [CrossRef] [PubMed]

62. Mason, N.W.; Mouillot, D.; Lee, W.G.; Wilson, J.B. Functional richness, functional evenness and functional divergence: The primary components of functional diversity. Oikos 2005, 111, 112-118. [CrossRef]

63. Laliberté, E.; Legendre, P. A distance-based framework for measuring functional diversity from multiple traits. Ecology 2010, 91, 299-305. [CrossRef] [PubMed]

64. R Core Team. R: A Language and Environment for Statistical Computing; R Foundation for Statistical Computing: Vienna, Austria, 2016.

65. Swenson, N.G. Functional and Phylogenetic Ecology in R; Springer: Berlin, Germany, 2014.

66. Waide, R.B.; Willig, M.R. Conceptual overview: Disturbance, gradients, and ecological response. In $A$ Caribbean Forest Tapestry: The Multidimensional Nature of Disturbance and Response; Brokaw, N., Crowl, T.A., Lugo, A.E., McDowell, W.H., Scatena, F.N., Waide, R.B., Willig, M.R., Eds.; Oxford University Press: New York, NY, USA, 2012; pp. 42-71.

67. Willig, M.R.; Walker, L.R. Disturbance in terrestrial ecosystems: Salient themes, synthesis, and future directions. Ecosyst. World 1999, 747-768.

68. Foster, R.B.; Brokaw, N.V. Structure and History of the Vegetation of Barro Colorado Island [Semideciduous Forest, Panama]; Smithsonian Institutional Press: Washington, DC, USA, 1982.

69. Brokaw, N.; Fraver, S.; Grear, J.S.; Thompson, J.; Zimmerman, J.K.; Waide, R.B.; Everham, E.M., III; Hubbell, S.P.; Foster, R. Disturbance and canopy structure in two tropical forests. In Tropical Forest Diversity and Dynamism: Findings from a Large-Scale Plot Network; Losos, E.C., Leigh, E.G., Eds.; University of Chicago Press: Chicago, IL, USA, 2004.

70. De Gouvenain, R.C.; Silander, J.A., Jr. Do tropical storm regimes influence the structure of tropical lowland rain forests? Biotropica 2003, 35, 166-180. [CrossRef]

71. Johnstone, J.F.; Allen, C.D.; Franklin, J.F.; Frelich, L.E.; Harvey, B.J.; Higuera, P.E.; Mack, M.C.; Meentemeyer, R.K.; Metz, M.R.; Perry, G.L. Changing disturbance regimes, ecological memory, and forest resilience. Front. Ecol. Environ. 2016, 14, 369-378. [CrossRef]

72. Griffith, M.P.; Noblick, L.R.; Dowe, J.L.; Husby, C.E.; Calonje, M.A. Cyclone tolerance in new world arecaceae: Biogeographic variation and abiotic natural selection. Ann. Bot. 2008, 102, 591-598. [CrossRef] [PubMed]

73. Basnet, K.; Scatena, F.N.; Likens, G.E.; Lugo, A.E. Ecological consequences of root grafting in Tabonuco (Dacryides excelsa) Trees in the Luquillo Experimental Forest, Puerto Rico. Biotropica 1993, 25, $28-35$. [CrossRef]

74. Mabry, C.M.; Hamburg, S.P.; Lin, T.C.; Horng, F.W.; King, H.B.; Hsia, Y.J. Typhoon disturbance and stand-level damage patterns at a subtropical forest in Taiwan. Biotropica 1998, 30, 238-250. [CrossRef]

75. Connell, J.H. Diversity in tropical rain forests and coral reefs. Science 1978, 199, 1302-1310. [CrossRef] [PubMed]

76. Sheil, D.; Burslem, D.F. Disturbing hypotheses in tropical forests. Trends Ecol. Evol. 2003, 18, 18-26. [CrossRef]

77. Paine, C.; Amissah, L.; Auge, H.; Baraloto, C.; Baruffol, M.; Bourland, N.; Bruelheide, H.; Daïnou, K.; Gouvenain, R.C.; Doucet, J.-L.; et al. Globally, functional traits are weak predictors of juvenile tree growth, and we do not know why. J. Ecol. 2015, 103, 978-989. [CrossRef]

78. Yang, J.; Cao, M.; Swenson, N.G. Why functional traits do not predict tree demographic rates. Trends Ecol. Evol. 2018, 33, 326-336. [CrossRef] [PubMed]

79. Thompson, J.; Brokaw, N.; Zimmerman, J.K.; Waide, R.B.; Everham, E.M.; Lodge, D.J.; Taylor, C.M.; García-Montiel, D.; Fluet, M. Land use history, environment, and tree composition in a tropical forest. Ecol. Appl. 2002, 12, 1344-1363. [CrossRef]

80. Swenson, N.G.; Erickson, D.L.; Mi, X.; Bourg, N.A.; Forero-Montaña, J.; Ge, X.; Howe, R.; Lake, J.K.; Liu, X.; $\mathrm{Ma}, \mathrm{K}$. Phylogenetic and functional alpha and beta diversity in temperate and tropical tree communities. Ecology 2012, 93, S112-S125. [CrossRef] 
81. Dale, V.H.; Joyce, L.A.; McNulty, S.; Neilson, R.P.; Ayres, M.P.; Flannigan, M.D.; Hanson, P.J.; Irland, L.C.; Lugo, A.E.; Peterson, C.J. Climate change and forest disturbances: Climate change can affect forests by altering the frequency, intensity, duration, and timing of fire, drought, introduced species, insect and pathogen outbreaks, hurricanes, windstorms, ice storms, or landslides. BioScience 2001, 51, 723-734. [CrossRef]

82. Niklas, K.J. Computing factors of safety against wind induced tree damage. J. Exp. Bot. 2000, 51, 797-806. [CrossRef] [PubMed]

83. Wood, C.J. Understanding wind forces on trees. In Wind and Trees; Coutts, M.P., Grace, J., Eds.; Cambridge University Press: Cambridge, UK, 1995.

84. Elsner, J.B.; Kossin, J.P.; Jagger, T.H. The increasing intensity of the strongest tropical cyclones. Nature 2008, 455, 92. [CrossRef] [PubMed]

85. Velden, C.; Olander, T.; Herndon, D.; Kossin, J.P. Reprocessing the most intense historical tropical cyclones in the satellite era using the advanced Dvorak technique. Mon. Weather Rev. 2017, 145, 971-983. [CrossRef]

(C) 2018 by the authors. Licensee MDPI, Basel, Switzerland. This article is an open access article distributed under the terms and conditions of the Creative Commons Attribution (CC BY) license (http:// creativecommons.org/licenses/by/4.0/). 